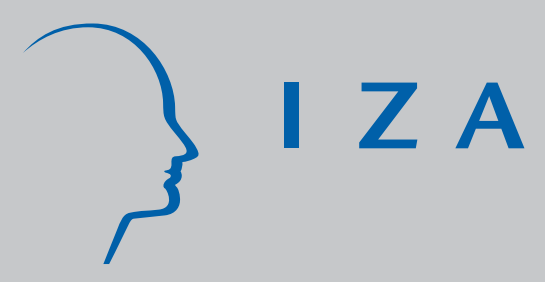

IZA DP No. 3000

Family Background and Income during the Rise of the Welfare State: Brother Correlations in Income for Swedish Men Born 1932-1968

Anders Björklund

MarkusJ äntti

Matthew J. Lindquist

August 2007 


\title{
Family Background and Income during the Rise of the Welfare State: Brother Correlations in Income for Swedish Men Born 1932-1968
}

\author{
Anders Björklund \\ SOFI, Stockholm University and IZA \\ Markus Jäntti \\ Abo Akademi University \\ Matthew J. Lindquist \\ Stockholm University \\ Discussion Paper No. 3000 \\ August 2007 \\ IZA \\ P.O. Box 7240 \\ 53072 Bonn \\ Germany \\ Phone: +49-228-3894-0 \\ Fax: +49-228-3894-180 \\ E-mail: iza@iza.org
}

\begin{abstract}
Any opinions expressed here are those of the author(s) and not those of the institute. Research disseminated by IZA may include views on policy, but the institute itself takes no institutional policy positions.
\end{abstract}

The Institute for the Study of Labor (IZA) in Bonn is a local and virtual international research center and a place of communication between science, politics and business. IZA is an independent nonprofit company supported by Deutsche Post World Net. The center is associated with the University of Bonn and offers a stimulating research environment through its research networks, research support, and visitors and doctoral programs. IZA engages in (i) original and internationally competitive research in all fields of labor economics, (ii) development of policy concepts, and (iii) dissemination of research results and concepts to the interested public.

IZA Discussion Papers often represent preliminary work and are circulated to encourage discussion. Citation of such a paper should account for its provisional character. A revised version may be available directly from the author. 
IZA Discussion Paper No. 3000

August 2007

\begin{abstract}
Family Background and Income during the Rise of the Welfare State: Brother Correlations in Income for Swedish Men Born 1932-1968*

The goal of this study is to examine trends in the importance of family background in determining adult income in Sweden. We investigate whether the association between family background and income in Sweden has changed for cohorts born 1932-1968. Our main finding is that the share of the variance in long-run income that is attributable to family background, the so-called brother correlation in income, has fallen by some 11 percentage points from 0.34 for the cohorts of brothers born in the early 1930s to below 0.23 for the cohorts born around 1950. From then on, the correlations have been more or less stable and are in line with earlier estimates. When we adjust income for the income return to years of schooling, we find constant brother correlations in income. The main effect is coming from changes in the distribution of schooling across cohorts. This finding is consistent with the hypothesis that education policies have been a key factor in equalizing life chances in Sweden.
\end{abstract}

JEL Classification: D1, D3, J62

Keywords: $\quad$ sibling correlation, intergenerational mobility, family background

Corresponding author:

Anders Björklund

Swedish Institute for Social Research (SOFI)

Stockholm University

SE-10691 Stockholm

Sweden

E-mail: anders.bjorklund@sofi.su.se

\footnotetext{
"We would like to thank seminar participants at ESPE 2007, the Nordic Summer Institute in Labor Economics 2007, London School of Economics, SOFI and Department of Economics at Stockholm University, and Umeå. Financial support from FAS (Swedish Council for Working Life and Social Research) is gratefully acknowledged.
} 


\section{Introduction}

Social scientists from many academic disciplines have for a long time been interested in the association between family background, in a wide sense, and socio-economic status during adult life. In the last 10 - 15 years, economists have become more active in this research field and have, in particular, focused on the relationship between family background and adult income. Empirical research on such issues has become feasible in some countries thanks to household panel data sets (such as the Panel Study of Income Dynamics and the National Longitudinal Survey in the United States, and the German Socio-Economic Panel) in which families have been followed from one generation to the next. In other countries, such as the Nordic ones and Canada, administrative register data have been used to connect family members to each other.

The most frequent analytical approach has been to estimate intergenerational income elasticities (or correlations) between fathers and sons. Solon (1999, 2002) summarizes such estimates for several countries. A less frequent, but very powerful approach is to estimate sibling correlations in income. The power of this approach comes from the fact that a sibling correlation tells us what fraction of the variation in the variable of interest (such as income) that can be attributed to factors that siblings share. Siblings who have grown up together, share both family factors, such as parental income, and neighborhood influences of various sorts, all of which affect their subsequent incomes. Thus, a sibling correlation is a broader measure of the importance of childhood conditions than an intergenerational one. ${ }^{1}$

Empirical research following these two approaches has produced a variety of interesting results. One of the most striking ones is the clear cross-national pattern that family background is more important for labor market achievement in the United States than in most

\footnotetext{
${ }^{1}$ Note also that as long as closely spaced siblings are used to estimate a sibling correlation, income is measured for more or less the same income distribution. Parents' and offsprings' incomes are by necessity measured many years apart. Intergenerational estimates are, therefore, complicated by the fact that income distributions might be very different for the two generations. In such cases the intergenerational elasticity will deviate from the intergenerational correlation.
} 
other rich countries. The Nordic countries turn out to have among the weakest associations between family background and labor market outcomes. Both estimated intergenerational income elasticities and sibling income correlations reveal such results. However, these results are limited in the sense that they have been obtained using data covering offspring (or siblings) that were born in the 1950s and early 1960 s. $^{2}$ It is, therefore, natural to ask whether this cross-national pattern has existed for a very long time, or if it is a more recent phenomenon, perhaps related to the rise of the ambitious Nordic welfare states.

The main goal of this study is examine trends in the importance of family background in determining adult income in, starting with cohorts born in 1932. The main challenge is that we need data that satisfy the following requirements: First, we must be able to connect family members - either siblings or parents and children - to each other over a long period of time. Second, we need income data that are comparable across time for these family members. Third, we need large samples to measure brother correlations with a precision that is high enough to allow us to detect significant changes in family associations over time. To meet these requirements, we make use of the unique opportunity offered by Swedish administrative register data sets held by Statistics Sweden. Its multigenerational register records the parents of all children born since 1932 onward. Income data from 1968 and onward are available from the tax assessment procedure. We use these data to estimate brother correlations in long-run income observed at ages 30 - 38 for closely spaced full siblings born 1932 - 1938, 1935 - 1941 and so on until 1962 - 1968.

\footnotetext{
${ }^{2}$ See Solon (2002) and Corak (2006) for surveys of intergenerational elasticities. See Björklund et al. (2002) for comparable estimates of brother correlations in earnings for the Nordic countries (Denmark, Finland, Norway and Sweden) and the United States; Björklund et al. (2004) also report sister correlations for the Nordic countries. Regarding studies that explicitly focus on trends, the recent Norwegian trend studies by Bratberg et al. (2005, 2007) only go back to the cohort of offspring born 1950. Pekkala and Lucas (2007) study intergenerational mobility using Finnish data going back to cohorts born in 1930 and find a decline in the intergenerational elasticity from the cohorts born in 1930 through the early 1950s. However, they only observe income from 1970 onward for all cohorts and generations, so it is likely that their inference on trends is affected by so-called life-cycle bias.
} 
The period covered by our data is quite long, so the cohorts that we analyze have grown up under markedly different circumstances. For example, several educational reforms took place during this period. The central theme of these reforms was to make the Swedish educational system more comprehensive and to extend the length of compulsory schooling. The fraction of each cohort that has gone to college has also increased substantially. To accommodate this expansion, new colleges have been established all over the country. The last cohorts were also affected by the expansion of daycare (or preschool) that started in the 1960s. Another change that could potentially affect the impact of family background is that hourly earnings and disposable income inequality fell during the 1960s and 1970s. ${ }^{3}$ Significant changes in the Swedish family structure also took place during this period. Divorce rates started to increase in the 1960s and cohabitation (rather than formal marriage) became more frequent. At the same time, many women entered the labor market, first in the 1960s and 1970s to mainly part-time jobs and later in the 1980s to full-time jobs. ${ }^{4}$

Our basic finding is that brother correlations in income have fallen by some 11 percentage points from 0.34 for the cohorts born in the early 1930s to 0.23 for the cohorts born around 1950. From then on, the correlations have been more or less stable and are in-line with earlier estimates. In an initial attempt to say something about the mechanisms driving this decline, we repeat the experiment adding a control for schooling. This results in constant, or even somewhat rising, brother correlations in income. Thus, changes in the quantity of schooling and/or returns to schooling seem to be important factors behind the decline in brother correlations in income. The main effect appears to be coming from changes in the

\footnotetext{
${ }^{3}$ See, e.g., Gustafsson and Uusitalo (1990) for an analysis of disposable income inequality for this period and Edin and Holmlund (1995) for hourly earnings inequality. Gustafsson and Uusitalo (1990) also show that there was no corresponding decline in total pre-tax factor income inequality over the same period; we use pre-tax factor income in this study.

${ }^{4}$ Women's change from part-time to full-time work during our observation period would complicate the interpretation of changes in sister correlations. This is one reason why we only estimate brother correlations in this study.
} 
distribution of schooling across cohorts. This finding is consistent with the hypothesis that school reforms have been a key factor in equalizing life chances in Sweden.

The rest of the paper is organized as follows. In Section 2, we present the longitudinal income models that we use to estimate our brother correlations in income. We also explain how we estimate the models and discuss various sources of bias. Section 3 describes the administrative data sources from which we have derived our samples as well as descriptive statistics for the cohorts we use in our analysis. The estimated correlations and sensitivity analyses are reported in Section 4. In Section 5, we present our attempts to account for the decline in sibling correlations. Section 6 concludes.

\section{Models and Estimation}

\subsection{Modeling Income}

To clarify the useful interpretation of the sibling correlation, suppose first that we have a perfect measure of long-run income at our disposal. Long-run income, $y_{i j}$, for sibling $j$ in family $i$ can be modeled as

$$
y_{i j}=\mu+\varepsilon_{i j},
$$

where $\mu$ is the population mean and $\varepsilon_{i j}$ is an individual-specific component with population variance $\sigma_{\varepsilon}^{2}$. The individual component represents the individual's position in the long-run income distribution, which is what we want to focus our attention on. It can be viewed as the sum of two components

(2)

$$
\varepsilon_{i j}=a_{i}+b_{i j},
$$


where $a_{i}$ is a permanent component common to all siblings in family $i$, and $b_{i j}$ is a permanent component unique to individual $j$ in family $i$, which captures individual deviations from the family component. The two components are independent by construction. Thus, the variance of $\varepsilon_{i j}$ can expressed as the sum of the stationary population variances of the family and individual components:

$$
\sigma_{\varepsilon}^{2}=\sigma_{a}^{2}+\sigma_{b}^{2}
$$

The share of the variance in long-run income that can be attributed to family background effects is

$$
\rho=\frac{\sigma_{a}^{2}}{\sigma_{a}^{2}+\sigma_{b}^{2}} .
$$

This share coincides with the income correlation of randomly drawn pairs of brothers, which is why $\rho$ is called a sibling correlation.

A sibling correlation can be thought of as an omnibus measure of the importance of family and community effects. It includes anything shared by siblings, -- -- parental income and parental influences such as aspirations and cultural inheritance, as well as things not directly experienced in the home such as school, church and neighborhood effects. Genetic traits not shared by siblings, differential treatment of siblings, time-dependent changes in neighborhoods, schools, etc. are captured by the individual component $b_{i j}$. If such non-shared factors are relatively more important than shared factor for incomes, the variance of the family effects will be small relative to the variance of the individual effects and the brother 
correlation will be low. The more important the effects that brother share are, the larger is the brother correlation.

We now turn to the practical case when we as researchers consider estimating long-run income by using panel data on annual income observations over a reasonably long period of time. Current income of sibling $j$ in family $i$ measured in year $t$ can be modeled as

$$
y_{i j t}=\mu_{t}+\varepsilon_{i j t},
$$

where $\mu_{t}$ is the population mean in year $t$ and $\varepsilon_{i j t}$ is an individual-specific term with an assumed constant population variance $\sigma_{\varepsilon}^{2}$. The error term, $\varepsilon_{i j t}$, can be viewed as the sum of three components

$$
\varepsilon_{i j t}=a_{i}+b_{i j}+v_{i j t}
$$

where (as before) $a_{i}$ is the permanent component common to all siblings in family $i$, and $b_{i j}$ is the permanent component unique to individual $j$ in family $i$. The new component, $v_{i j t}$, represents measurement errors and transitory shocks to income and age-related income differences. The model in (5) and (6) may be more realistic in multiplicative form. Thus all components are logged and we consider the sibling correlation of log income.

This model can be further generalized by allowing the transitory shocks to be correlated across time. While, in principle, the full family of ARIMA processes is available, low order ARMA models are most practical. In particular, we examine the consequences for our estimated sibling correlations of allowing the transitory error to follow a stationary, firstorder autoregressive process 


$$
v_{i j t}=\delta v_{i j t-1}+\eta_{i j t}
$$

where $\eta_{i j t}$ is a mean zero, constant variance, $\sigma_{\eta}{ }^{2}$, random shock to current income. This $\operatorname{AR}(1)$ process reflects the potential for persistence in transitory shocks, but will also pick up income changes due to life-cycle income profiles. It should be noted that we assume the white-noise errors in (7) to be uncorrelated across brothers.

\subsection{Estimation}

In order to calculate the sibling correlation in long-run income, $\rho$, we need estimates of the within-family variation, $\sigma_{b}^{2}$, and the between-family variation, $\sigma_{\mathrm{a}}^{2}$. The two most common methods used in this context are the traditional analysis of variance (ANOVA) method and the restricted maximum likelihood (REML) method. The ANOVA method, however, has several drawbacks, particularly when dealing with unbalanced data as we are in this study. Our data are unbalanced because we include families with different numbers of brothers.

The first, most serious drawback is that the distributional properties of the ANOVA estimators for unbalanced data are, in fact, not known. Second, we have no way of comparing the different ANOVA methods that are applied to unbalanced data in order to judge which method is most appropriate. Third, there is nothing to prevent ANOVA estimates of variance components from taking on negative values. ${ }^{5}$

The REML method, on the other hand, is known to produce consistent estimates of the necessary variance components even when the data are unbalanced (Searle et al., 1992). As such, it is clearly more suited to the task at hand. The only potential drawback of this method is that it forces us to make a number of a priori distributional assumptions concerning

\footnotetext{
${ }^{5}$ See Searle et al. (1992) for more information on these and other topics concerning the estimation of variance components. Solon et al. (1991) and Björklund et al. (2002, 2004) apply the ANOVA method. Mazumder (2007) compare the performance of the ANOVA and REML methods and finds quite similar estimates from the two methods. Thus, we feel confident to compare our results with those in previous research.
} 
the different variance components. But we would have been forced to do this anyway if we had used ANOVA estimates in any form of hypothesis testing. ${ }^{6}$

We use multiple-year observations on annual income to estimate the following mixed-effects model

$$
y_{i j t}=\mathbf{X}_{i j t} \boldsymbol{\beta}+a_{i}+b_{i j}+v_{i j t}
$$

where $a_{i} \sim N\left(0, \sigma_{\mathrm{a}}{ }^{2}\right), b_{i j} \sim N\left(0, \sigma_{\mathrm{b}}{ }^{2}\right)$ and $v_{i j t} \sim N\left(0, \sigma_{v}{ }^{2}\right)$. This formulation allows for multiple fixed effects, $\boldsymbol{\beta}$. The multiple fixed-effects model matrix $\mathbf{X}_{i j t}$ includes a third-order polynomial in age in order to control for a deterministic age-income profile, reflecting the fact that individuals of different ages may find themselves at different points in their life-cycle income profile. Since we have multiple-year observations on current income, $\mathbf{X}_{i j t}$ might also include year dummies, representing more general time effects such as inflation, business cycle and cohort effects. However, our age variable is perfectly co-linear with these time dummies. The controls for age and the intercept pick up differences in economic conditions and cohort effects instead. ${ }^{7}$

\subsection{Estimation Biases}

\footnotetext{
${ }^{6}$ The difference between the REML and full maximum likelihood (ML) approaches is that the ML estimates are obtained from joint maximization of the likelihood function with respect to both the fixed effects $\beta$ and the variance components corresponding to equation (6) or (3). As discussed by Laird and Ware (1982), Harville (1977) and Dempster et al. (1981), REML estimation is in general preferable to ML, since the latter does not take into account the loss of degrees of freedom from the use of the residuals (rather than true errors) to estimate the variance components. While this inconsistency in ML would unlikely be important with the sample sizes we work with, there is no gain in working with ML rather than REML here. Searle et al (1992) and Pinheiro and Bates (1999) give readable expositions of estimating such models. Pinheiro and Bates (1999) discuss estimation under autocorrelated errors structures.

${ }^{7}$ We estimate the models using the xtmixed procedure in Stata (9.0). To estimate the model with autocorreacted $\mathrm{AR}(1)$ errors, we have used the lme package in $\mathrm{R}$ (Pinheiro and Bates, 1999). The computational burden was quite considerable. We needed to estimate the models on 64-bit processors in order to overcome the 3 gigabyte limit on process size built into 32-bit operating systems.
} 
In our model of long-run income, the sibling correlation, $\rho$, was derived under the assumption that the transitory factors, $v_{i j t}$, were uncorrelated with the permanent components of income, $a_{i}$ and $b_{i j}$. To ensure that this condition holds, we estimate equation (8) using a large representative sample of the Swedish population. In contrast to this, many of the early estimates of sibling correlations were based on small, unusually homogeneous samples (e.g., Olneck, 1977; Kearl and Pope, 1986). More importantly, all of the studies prior to Solon et al. (1991) were based on single-year measures of current income, which (for lack of better data) was used as a proxy for long-run income. Furthermore, the age structure of the sample was most often ignored. As discussed in Solon et al. (1991), transitory shocks to income, age effects and cohort effects all tend to bias estimates of $\rho$ strongly downwards. These biases become even more serious in homogeneous samples.

Solon et al. (1991) proposed an ANOVA methodology for unbalanced data specifically designed to deal with these biases. Data from the PSID gave them multiple-year measures of current income. This allowed them to model transitory shocks to income as a first-order autoregressive process. They also included fixed age and year effects in order to deal with life-cycle, cohort and general time effects. Their methodology has since been used in several later studies (e.g., Björklund et al., 2002, 2004; Levine and Mazumder, 2007) and has been extended to the REML method by Mazumder (2007).

We expand upon Solon et al.'s (1991) list of biases to include the phenomenon of life-cycle bias. Haider and Solon (2006) and Böhlmark and Lindquist (2006) demonstrate that the association between current and lifetime income varies strongly over the life-cycle. When this is true, the use of current income as a proxy for lifetime income leads to inconsistent parameter estimates, also known as life-cycle bias, even when the proxy is used as a dependent variable (as it is here) ${ }^{8}$

\footnotetext{
${ }^{8}$ For theoretical treatments of life-cycle bias in intergenerational estimates, see Jenkins (1987) and Grawe (2006).
} 
Although this possibility has not been discussed in the previous literature, sibling correlations that use a single- or even a multiple-year measure of current income as a proxy for permanent income status will most likely suffer from this life-cycle bias. In Appendix A, we illustrate the basic idea underlying life-cycle bias in the context of sibling correlations using a rather simple income generating process. Our solution to this potential problem in this study is to stick to measuring income at the same ages for all cohort groups. If life-cycle bias is present but reasonably constant over time, our conclusions about trends will not be affected. Our choice has been to have income centered around age 34, an appropriate choice in Sweden, based on Böhlmark and Lindquist's (2006) examination of the association between annual and lifetime income.

\section{The Data}

\section{$\underline{3.1 \text { Data Description }}$}

To identify siblings for several cohorts of Swedish brothers, we have extracted samples from Statistics Sweden's multigenerational register. This register covers all persons who were born in Sweden from 1932 onwards and have lived in Sweden (folkbokförda) at any time since 1961. The register identifies the biological and adoptive parents and siblings of these persons. For the very first cohorts born in 1932 and 1933, only 37 and 69 percent of mothers, and 32 and 62 percent of fathers, are identified. But for the 1934 cohort the corresponding numbers are as high as 81 and 74 percent, and from then on the identification improves gradually to 99 percent of mothers and 95 percent of fathers in the 1950 cohort.

We have extracted a 35 percent random sample of those born 1932 - 1967 from this register. For these individuals, we have identified all biological and adoptive siblings and parents and merged them to our analysis sample. ${ }^{9}$ There are very few adopted siblings and

\footnotetext{
${ }^{9}$ Note that some siblings are born in 1968.
} 
their frequency declined during the 1960s, so we have only included biological brothers in our analysis.

The multigenerational register does not provide any information about family connections via cohabitation. To get such information from Swedish registers, one must instead use the censuses. The first census that is available for research purposes was done in 1960 and subsequent ones were done every fifth year until 1990. Our data set also includes "social" siblings defined as those children who lived in the same census household, as well as "social" parents as the adults in the households with children. Of course, most social siblings and parents are also biological ones, so there are no strong reasons to suspect that the results are very sensitive to the choice of sibling definition. Indeed, Björklund et al. (2002) estimate brother correlations for cohorts born 1948 - 1965 by both a biological and a social sibling definition and found only small differences between the two definitions; 0.28 for biological brothers and 0.25 for social ones. So we stick to using biological siblings in our analysis of trends in Sweden. This allows us to go further back in time.

We have merged income data from the official Swedish tax register for 1968 to 2002 with our sibling sample. Our main income variable is total income from all sources of income (sammanräknad inkomst), or pre-tax total factor income. This variable is available from 1968 onward. As a complement, we use labor earnings (arbetsinkomst), but this variable is only available from 1974 onward. Although we would (of course) prefer to have data to allow us to go even further back in time, the income data for 1968 - 2002 allow us to estimate sibling correlations in income using yearly data centered around age 34. This is crucial, since we do not want life-cycle bias to affect our inference about trend in sibling correlations.

One major change in the income concept took place between 1973 and 1974 when some social benefits, most notably unemployment compensation, sickness benefits and parental leave benefits became taxable and were included in the income concept used in the income declaration process. Because parental leave benefits were mainly used by mothers 
and, at the time, were of rather short duration, the problematic transfers for our purposes are unemployment compensation and sickness pay. Fortunately, we have these benefits at our disposal for the years 1974 - 1980 so we can check the sensitivity to their inclusion from 1974 onward.

Our empirical model is based on the logarithm of annual income, so we have to make a decision about how to treat zero income observations as well as very low income observations. In our baseline estimations, we have followed the convention from previous research and excluded all zero observations. We also strived for a similar lower income limit over time and decided to use the largest of the minimum income observation for any year as the lower limit for each year. This lower limit is SEK342 $(\approx \$ 5)$ in 2002 prices and thus this real income limit is applied to all years. We also exclude individuals who did not survive to the end of the observation window.

We split our sample into eleven partly overlapping cohorts. The first cohort consists of brothers born 1932 - 1938. We then add three years to each consecutive cohort, so that the second cohort consists of brothers born 1935 - 1941. The last cohort consists of brothers born 1962 - 1968. Thus, our sibling correlations are estimated using closely spaced brothers only, i.e. born within seven calendar years of each other.

\subsection{Descriptive Statistics}

Descriptive statistics for the eleven cohorts we study are reported in Table 1. By following the rule that income should be observed in the age range 30 - 38 years, the mean age when income is observed ranges from 34.9 to 33.5 in our cohort groups. By construction of the sub samples, this age is somewhat higher for the first cohorts and somewhat lower for the last ones. These age differences are obviously small, but we have nonetheless checked that they do not affect our inferences about trends in the correlations. 
The sample sizes, in terms of both the number of families and the number of individuals, are very large for each cohort group, which promises high precision in the estimates. We have followed the convention from previous studies to include singletons, which contribute to the precision of the estimation of the family variance component. Thus, the number of individuals is only some $20-30$ percent higher than the number of families. Real log annual income fell slightly during the sluggish 1970s and 1980s, but rose again at the end of the observation period. The standard deviation of log annual income has increased over time. As mentioned in the introduction, this pattern is consistent with previous findings based on overall inequality measures for this income concept. Inequality of disposable income and hourly labor earnings, on the other hand, fell from 1960 to the early 1980s, when they started to rise again.

The last column of the table gives information about the average number of income observations per individual and the fraction zeros among potential income observations. Note that the first two cohort groups are observed, on average, during a shorter period of time. The fraction of missing (or zero) income observations is low, ranging from 3.1 percent for the first cohort group to 0.7 for the sixth group. It is important to note, however, that these zeros do not appear to be clustered within families.

\section{Results}

\section{$\underline{4.1 \text { Baseline results }}$}

We report our baseline results in Figure 1. The main impression is that the brother correlation declined significantly for the first five cohort groups, i.e., from the groups born 1932 - 1938 through 1944 - 1950. For later cohorts, the brother correlation does not change very much. Since the estimates from then on are in the range 0.22 to 0.25 , we conclude that brother correlations have been quite stable in the latter part of the period we study. The estimates for 
the latter part of the period are also in the same ballpark as those in previous Swedish research.

The decline from the first cohort (born 1932 - 1938) to the fifth (born 1944 1950 ) is from 0.344 to 0.232 . Thus, the fraction of income inequality attributable to family and community factors shared by closely spaced full brothers fell by just over 11 percentage points. We find this decline sizeable. Although 0.34 is below the estimates generally obtained for the United States for later cohorts, it is striking that a decline of this magnitude took place over such a short period. If this finding is robust to a number of sensitivity tests, an important next task is to understand the reasons for the decline in the importance of family background in income.

Before turning to the sensitivity analyses, we look at the evolution of the variance components underlying the estimated sibling correlations in our baseline case. We report these components in Figure 2. We can see that the estimated variance of the family components first fell from the first cohort group to the fourth, and then started to rise again from the fifth group onwards. The latter rise was larger than the decline during the former period, so this variance component ended at a higher level than it started. The figure also shows that both the individual and the transitory variance components have risen over time. Thus, the large initial fall in the sibling correlation was caused by the fall in the family component. The subsequent, stable pattern of the sibling correlation is created by a "balanced" increase in both the family and the individual component. The last part of figure 2 shows that the family component's share of total income variation (including the transitory part), just like the sibling correlation in long-run income, fell by 11 percentage points.

\subsection{Sensitivity analyses}

Our baseline specification and sample definition involve a number of somewhat arbitrary choices. We investigate whether our results are robust with respect to a few of these decisions. 
First, we consider our way of dealing with very low and zero (and missing) income observations. The reason that such observations are typically omitted from the samples used in the estimations in this literature is that the underlying model, with permanent family and individual components as well a transitory individual component, are usually fitted in logarithmic form. We report the number of missing income observations in Table 1 and at most they were 3.1 percent of all observations. These observations might represent truly low, or zero, incomes, but might also be missing due to missing reports to the tax authority. An alternative to omitting such observations is to assign a very low income to them . By doing so, and then logging this low value, one will give these observations very high weights in the estimations. Although we are skeptical of this alternative procedure, we want to illustrate that the consequences can be dramatic. In Figure 3a, we have set the missing values to SEK 1 $(\approx \$ 0.15)$. It turns out that we then get a different pattern, namely one of weakly rising sibling correlations, rather than the substantial decline of our baseline case. Furthermore, these new estimates are much smaller in magnitude than our baseline estimates.

One could also argue the opposite, namely that very low, but positive income observations are inaccurate and poor indicators of long-run income. In that case, one might get more accurate results by eliminating these observations and by raising the lower income bound. In Figure 3b, we report results where we have done so. It turns out that the clear decline in our baseline case remains even when we raise the lower bound by the factors 10 and 100. In Figure 3c, we report the results from an alternative experiment which treats zeros (and missing) and low incomes in what we believe to be a more appropriate fashion. Here, we have taken the mean of all income observations (including the zero and missing observations) from all nine years at ages 30 - 38. Then we logged this mean income and used it in the estimations. In doing so, we take these observations into account, but they do not get the extremely high weights that they get when the single income observation is logged. The price we pay is that we do not get a nice multiplicative model of the three earnings inequality 
components; the transitory component is eliminated. But since the estimation of the transitory component is not the main purpose of our study, we are willing to pay this price. The results in Figure 3c show that the estimated brother correlations using this approach are very close to our baseline case. We, therefore, conclude that our basic result of falling correlations is not an artifact of our treatment of low income observations.

In order to avoid the problem of life-cycle bias in our estimates, we chose to restrict our income variable to those observed between the ages of 30 and 38 years. As a rough check on the importance of the imposed age limits, we have re-estimated our trend using incomes for the ages 30 - 52. The results from this exercise are reported in Figure 4. We can see that there is a clear decline in the brother correlation even when the period over which we observe individual income is extended in this way. Indeed, the decline from the first cohort group to the last one is almost exactly the same as in the baseline. However, one must keep in mind that the estimates are comparable only for the first five cohort groups since from cohort group six onwards, the oldest individuals are younger than 52 years in 2002, the last year for our income observations. If we restrict interest to the older cohort groups $1-5$, we find a smaller decline over time, but one which is nonetheless statistically significant.

Third, we should find out whether the results are affected by the change in the income concept that took place between 1973 and 1974. The major change for men was the inclusion of unemployment and sickness benefits in pre-tax factor income from then on. Since we have access to individual data for these transfers for the years 1974-80, we can investigate whether the results become clearly different when we deduct these transfers from total income. The results, reported in Figure 5, do not suggest that this is the case. We conclude that our basic finding is robust with respect to this change in the income concept.

We have also estimated models with labor earnings instead of total factor income. These estimations, however, started with data from 1974, so we only have comparable estimates for cohort group five onward. The estimated brother correlations are 
very close to those using total income -- the deviations were at most .02. Thus, we conclude that the stable pattern that we have found for brother correlations in total income also can be found for labor earnings. However, it is an open question whether the decline for the earlier previous cohorts also has taken place in brother correlations in labor earnings.

Lastly, we have, examined if the trend in the sibling correlation is sensitive to autocorrelation in the transitory errors. Specifically, we re-estimate the baseline model, but now with an error term that follows an AR(1) process as in equation (7). The resulting sibling correlations are shown in Figure 6, along with the baseline. The level of the sibling correlation is substantially higher - now, about 7 to 8 percentage points more of the variation in permanent income is accounted for by the variance in family effects. However, the trend in the sibling correlation is not affected. The pattern here too is one of a declining importance of family background - albeit at a uniformly higher level than when the error is assumed to be white noise. $^{10}$

Inspection of the estimated variance components shows that this upward shift in the level of our sibling correlations is due to a decrease in the individual-level variation, with no change in the family-specific component. Intuitively, this makes sense. The sizeable AR(1) autocorrelation parameter - varying between 0.58 and 0.62 - picks up a substantial part of the (across time) constant individual specific variation.

The autocorrelated shocks are assumed to be uncorrelated across brothers, which means they do not reduce the variance of the family specific component. This increase in the sibling correlation through a decline in the individual-specific component is what is observed in other studies as well. For instance, Mazumder (2004) reports an increase of .04 in the correlation, using the exact same sample from the NLSY as in the white-noise case for the U.S.

\footnotetext{
${ }^{10}$ Note that we do not provide confidence bounds to the estimated brother correlations in Figure 8, since for many of our cohorts, the estimation procedure in R, lme, was unable to estimate the variance of the estimated variance components.
} 
The reason to worry about autocorrelation in the transitory error is that if the error process had undergone substantial change across time, this might have led us to observe a decline in sibling correlations even if none had in fact taken place. In particular, since the effect of a high autocorrelation is to reduce individual-specific variation and thus increase the family component's relative importance, a decline in the autocorrelation might increase the individual-specific component, reduce the sibling correlation and lead us to erroneously conclude that the share of family background had declined. This appears not to be the case.

\section{Understanding the fall in income correlations among brothers}

Having found a sizeable and robust decline in brother correlations in income from the cohorts born in the 1930s and 1940s to those born in the 1950s and 1960s, the next natural question to address is: Why has the importance of family background in determining adult income declined over time? The rise in the Swedish welfare state is one candidate explanation, but it is not a very precise one. The expansion of the welfare state included many different components, such as education policies of various sorts, housing policies, and transfer policies for the poor. In order to gain some clues about what type of mechanisms that might have been at work, we continue in section 5.1 with an analysis of the role of education. However, other factors not directly related to the expansion of the welfare state could have also made a difference. In section 5.2, we offer a short discussion of the role of changes in family structure as another explanation of the evolution of our brother correlations.

\section{$\underline{5.1 \text { Accounting for education }}$}

We study the contribution of education in two steps. First, we "account" for the role of education in the estimated brother correlations by adding schooling variables with associated coefficients to the multiple fixed-effects matrix $\mathbf{X}$ in (8) above. In doing so, we estimate 
income correlations among brothers using an income measure that is purged of the impact of education (and of variables correlated with education). ${ }^{11}$ Second, we investigate whether it is the quantity of schooling or the income return to schooling that accounts for the changes in the income correlations among brothers. To do this, we first look at the evolution of brother correlations in years of schooling. We then go on to investigate the role of the income return to education by keeping the schooling coefficient constant for all cohorts.

Administrative register data on the Swedish population's education are available from two sources. First, the 1970 census made a special effort to collect good nation-wide data on education. Second, in the mid-1980s, Statistics Sweden started a special education register covering the whole population. This register started out with the information in the 1970 census, and was updated with reports from schools and various surveys. We use these two data sources in the following way. We strive for measuring education at age 31 or older and thus we use the 1970 census for cohorts born 1932 - 1939, the 1990 version of the education register for cohorts born 1940 - 1959, and the 1999 version of the register for cohorts born 1960 - 1968. We infer years of schooling from seven main levels of education reported in these registers. ${ }^{12}$

We report descriptive statistics in Table 2. The second column shows that, as expected, the level of schooling has increased over time. This column also shows that the standard deviation of years of schooling was quite stable for the first five cohort groups and then fell by about a third. Taking into account that mean years of schooling increased over time, a relative measure of schooling inequality such as the coefficient of variation fell very little from the first to the fifth cohort group and then quite strongly for the rest of the period. The columns for the educational levels, denoted by the imputed years of schooling, show that

\footnotetext{
${ }^{11}$ Mazumder (2007) performs such an analysis on US data and offers a further explanation of the approach. See also Levine and Mazumder (2007), who distinguish between years of schooling and the monetary return to years of schooling.

${ }^{12}$ We assign years of schooling as follows: 7 for old primary school, 9 for new compulsory school, 11 for short high school, 12 for long high school, 14 for short university, 15.5 for long university and 19 for a Ph.D.
} 
the decline in schooling inequality can be mainly attributed to the fact that men have moved up from the lowest educational level to the next ones. The last column reports the coefficient for years of schooling obtained when regressing the log of income on years of schooling and the age and year variables included in the multiple fixed-effects matrix $\mathbf{X}$ in equation (8) above. It appears that the evolution of the returns to schooling displays a U-shaped pattern as expected from the returns-to-schooling literature. ${ }^{13}$

In Figure 7, we report the estimated sibling correlations when we have purged income from the impact of years of schooling. ${ }^{14}$ It turns out that these correlations are quite stable over the whole period. Thus, we conclude that there is something associated with schooling that drives the decline in the overall sibling correlations. Ideally, we would now like conduct a formal decomposition analysis that breaks the impact of education down into changes in the quantity (years and/or distribution) of schooling and changes in the income return to schooling. While we are not aware of any such decomposition technique, we can attempt to illustrate the differential roles of quantities and prices.

In Figure 8, we report estimated brother correlations in years of schooling. ${ }^{15}$ These correlations are, as expected from previous research, higher than the income correlations. Our estimates cluster just below 0.50. Compared to the income correlations, the schooling correlations are more stable across cohorts. The only notable change is the one from 0.52 for the first cohort group to 0.48 for the second, followed by another small decline to 0.46 for the third group. In all this is a decline of 0.06 , which can be compared with the decline of 0.07 for the income correlations for the first three cohorts and 0.11 for the first five cohorts. After this initial drop, we find a remarkable stability in the brother correlation in schooling. This fall in the sibling correlation could potentially explain part of the decline in

\footnotetext{
${ }^{13}$ See e.g. Gustavsson (2006) for a recent overview.

${ }^{14}$ We have also used a more flexible specification with dummies for each level of education, but the results were basically the same.

${ }^{15}$ It should be noted that the REML procedure we use to estimate the variance components rely on the outcome being normally distributed. This assumption may not be valid for years of schooling,
} 
the sibling correlation in income, at least for the first three cohorts. At the same time, the returns to education fell for the first five cohorts, which combined with the falling (and then stable) sibling correlation in schooling may also be part of the story.

To investigate the relative roles of prices - the return to schooling - and quantities - the amount and distribution of years of schooling - in accounting for the observed decline in the sibling correlation, we have estimated sibling correlations for incomes with the return to schooling held constant at the level received by our first cohort $(0.069)$. We have subtracted from each member of each cohort their schooling times the schooling coefficient for that cohort, and added in their schooling times 0.069 . Thus, all members of a cohort get the return they would have had, if the return to schooling had remained constant across all cohorts.

The results are shown in Figure 9. The estimated trend is very similar to that found for our base case in Figure 1, albeit that the decline is a little smaller, being around 0.10 as opposed to 0.12 in the base case. Also, the decline with the return to schooling held constant in Figure 9 declines less rapidly than the base case, with a reasonably even secular decline across all cohorts (with the exception of the hump for cohort 8). We conclude that, although changes across cohorts in the return to education appear to have had an effect on the sibling correlation, the broad pattern of a substantial secular decline is still valid once we standardize the return to schooling. Thus, something in the distribution of years of schooling is likely to have a substantial role in the change in the importance of family background for adult male income in Sweden. Levine and Mazumder (2007) also report a negligible role of changes in the returns to schooling. This finding is consistent with the hypothesis that school reforms have played a key role in equalizing life chances in Sweden.

\subsection{Other factors: family structure}


Although our main motivation for this study is to learn how the relationship between income and family background evolved over the period when Sweden's welfare state expanded substantially, it is important to recognize that a relationship such as the sibling correlation in income might be driven by quite different factors. Another candidate explanation is changes in family structure that might have had an impact on what brothers share of their family and neighborhood background. An obvious dimension of family structure is the age structure of the siblings. Most likely, closely spaced siblings share more background influences than more widely spaced ones. For example, closely spaced siblings are exposed to the same "shocks" of various sorts, be it parental income changes or unemployment experiences or parental separation.

In Table 3, we report two measures of family structure from the samples we have used in our estimations, namely (i) the average number of brothers and (ii) the average age difference between the brothers. Both variables are measured for brothers within the age span of each cohort that we use in our estimations. The general pattern is that neither dimension of family structure has changed much over the period of our study. The number of brothers per family ranges from 1.20 to 1.22 , which is consistent with the very stable cohort fertility rates close to 2.0 for Swedish women over the whole last century, see e.g. Björklund (2006). The average age difference between brothers did not change much either; the range is from 2.52 to 2.74 and only from 2.67 to 2.74 if the very first cohort group is eliminated. We find it quite unlikely that the sizeable decline in the brother correlation in long-run income from the cohorts born in the mid 1930s to those born around 1950 can be attributed to factors such as family size and the spacing of children. Nonetheless, we find it an interesting avenue for future research to explore how various dimensions of family structure affect similarities and differences among siblings.

\section{Conclusions}


We have found that factors related to family background were more important for the incomes of Swedish men born in the 1930s and 1940s compared to those born during the 1950s and have been stable since then for cohorts born through 1968. Our estimated brother correlations in total factor income fell from 0.34 for men born in the early 1930s to 0.23 for men born some 15 years later. During the subsequent 15 years, the estimated brother correlations are quite stable. Our conclusion that there is a substantial decline in the importance of family background in income is robust to a number of sensitivity tests.

In order to say something about the mechanisms driving this decline, we introduced years of schooling into the analysis. First, we re-estimated our brother correlations in income after having purged income from the income effect of years of schooling. We found that such correlations have been stable over time, which brought us to the conclusion that schooling (or something related to schooling) is able to account for the decline in the income correlations among brothers. Then we analyzed the role of schooling by examining brother correlations in years of schooling and by constructing a counterfactual with constant income returns to schooling. From this experiment, we conclude that changes in the distribution of schooling across cohorts appear to be more important than changes in the returns to schooling for explaining the observed decline in the brother correlations in income. This finding is consistent with the hypothesis that education policies have played a key role in equalizing life chances in Sweden.

Needless to say, more research is required to find out about the mechanisms behind the changes we have observed. It would be both interesting per se and useful for analytical purposes to know whether intergenerational income relationships also declined over this period. The decline in income correlations among brothers could, in principle, be caused by a weaker impact of parental income on offspring, or by a weakening of factors that are orthogonal to parental income, or by some combination of these effects. Unfortunately, Swedish register data on income are not available long enough back in time to let us estimate 
intergenerational income associations for the same cohorts for which we have estimated brother correlations.

Using more readily available, non-income data, sociologists' research on intergenerational class mobility in Sweden suggests that relative class-mobility rates (social fluidity) rose somewhat for the cohorts for which we observed falling correlations among brothers (Jonsson 2004). Because social class and long-run income are quite strongly correlated, we would guess that intergenerational income mobility also fell during this period of time. However, considering the very different metrics used in these two strands of literature it is hard to translate the changes in intergenerational class mobility into changes in intergenerational income associations. Thus, a cautious conclusion is that at least a part of the decline in income correlations among brothers may be attributed to weaker associations in income between fathers and sons.

\section{References}

Björklund, Anders (2006), "Does family policy affect fertility? Lessons from Sweden,” Journal of Population Economics, 2006 (1): 3-24.

Björklund, Anders, Tor Eriksson, Markus Jäntti, Oddbjörn Raaum and Eva Österbacka (2002), "Brother Correlations in Denmark, Finland, Norway and Sweden Compared to the United States,” Journal of Population Economics 15 (4): 757-72.

Björklund, Anders, Tor Eriksson, Markus Jäntti, Oddbjörn Raaum and Eva Österbacka (2004), "Family Structure and Labour Market Success: The Influence of Siblings and Birth Order on the Earnings of Young Adults in Norway, Finland and Sweden,” in M Corak (ed.), Generational Income Mobility in North America and Europe. Cambridge; Cambridge University Press, 2004, 207-25.

Bratberg, Espen, Øivind Anti Nilsen and Kjell Vaage "Intergenerational Earnings Mobility in Norway: Levels and Trends,” Scandinavian Journal of Economics 107(3): 419-35.

Bratberg, Espen, Øivind Anti Nilsen and Kjell Vaage (2007), "Trends in Intergenerational Mobility across Offspring's Earnings Distribution in Norway," Industrial Relations 46(1): $112-28$.

Böhlmark, Anders and Matthew J. Lindquist (2006), "Life-Cycle Variations in the Association between Current and Lifetime Income: Replication and Extension for Sweden,” Journal of Labor Economics 24(4): 879-96. 
Corak, Miles (2006), "Do poor children become poor adults? Lessons for public policy from a cross-country comparison of generational earnings mobility," Research on Income Inequality 13(1): 143-88.

Dempster, A. P., Rubin, D. B., and Tsutakawa, R. K (1981), "Estimation in covariance components models,” Journal of the American Statistical Association, 76(374): 341-53.

Edin, Per-Anders and Bertil Holmlund (1995), “The Swedish Wage Structure: The Rise and Fall of Solidarity Wage Policy,” in R. Freeman and L. Katz (eds.) Differences and Changes in Wage Structures, University of Chicago Press.

Grawe, Nathan (2006), "Life-cycle bias in estimates of intergenerational earnings persistence,” Labour Economics 13(5): 551-70.

Gustafsson Björn and Hannu Uusitalo (1990), "Income Distribution and Redistribution during Two Decades: Experiences from Finland and Sweden,” in Inga Persson (ed.) Generating Equality in the Welfare State: The Swedish Experience, Norwegian University Press.

Gustavsson, Magnus (2006), “The evolution of the Swedish wage structure: new evidence for 1992-2001,” Applied Economics Letters 13: 279-86.

Haider, Steven and Gary Solon (2006), "Life-Cycle Variations in the Association between Current and Lifetime Income,” American Economic Review 96(4): 1308-20.

Harville, David A. (1977) "Maximum likelihood approaches to variance component estimation and to related problems," Journal of the American Statistical Association, 72(358): 320-38.

Jenkins, Stephen (1987), "Snapshots versus movies: "lifecycle biases" and the estimation of intergenerational earnings inheritance,” European Economic Review 31 (July): 1149-58.

Jonsson, Jan O. (2004) “Equality at a Halt? Social Mobility in Sweden, 1976-99," in Richard Breen (ed.), Social Mobility in Europe. Oxford: Oxford University Press.

Kearl, J. R. and Clayne L. Pope (1986), "Unobservable Family and Individual Contributions to the Distributions of Income and Wealth,” Journal of Labor Economics 4(3): 48-79.

Laird, Nan M. and Ware, James H (1982), "Random-effects models for longitudinal data," Biometrics, 38(4): 963-974.

Levine David and Bhashkar Mazumder (2007), “The growing importance of family: Evidence from brothers’ earnings,” Industrial Relations 46(1): 7-21.

Mazumder, Bhashkar (2004), "Sibling Similarities, Differences and Economic Inequality,” Federal Reserve Bank of Chicago, Working Paper 2004-13.

Mazumder, Bhashkar (2007), "Sibling similarities and economic inequality in the US," Journal of Population Economics, forthcoming. 
Olneck, Michael R. (1977), "On the Use of Sibling Data to Estimate the Effects of Family Background, Cognitive Skills, and Schooling: Results from the Kalamazoo Brother Study," in P. Taubman (ed.), Kinometrics: Determinants of Socioeconomic Success within and between Families, North-Holland, Amsterdam.

Pekkala, Sari and Robert E. B. Lucas (2007), "Differences across Cohorts in Finnish Intergenerational Income Mobility,” Industrial Relations 46(1): 81-111.

Pinheiro, José C. and Douglas M. Bates (1999), Mixed-Effects Models in S and S-PLUS. Statistics and Computing, Springer-Verlag, New York.

Raaum, Oddbjörn, Kjell-Gunnar Salvanes and Erik Sørensen (2006), “The neighborhood is not what it used to be,” Economic Journal 116(1): 200-22.

Searle, Shayle R., George Casella and Charles McCulloch (1992), Variance Components, John Wiley \& Sons, New York.

Solon, Gary, Mary Corcoran, Roger Gordon and Deborah Laren (1991), “A Longitudinal Analysis of Sibling Correlations in Economic Status," Journal of Human Resources 26(3): 509-34.

Solon, Gary (1999), "Intergenerational Mobility in the Labor Market," in O. C. Ashenfelter and D. Card (eds.) Handbook of labor economics vol. 3A. Elsevier, Amsterdam, North Holland.

Solon, Gary (2002), "Cross-country differences in intergenerational earnings mobility," Journal of Economic Perspectives 16(3): 59-66.

\section{Appendix A. Life-Cycle Bias in Sibling Correlations}

In this Appendix, we expand upon Solon et al.'s (1991) list of biases to include the phenomenon of life-cycle bias. Haider and Solon (2006) and Böhlmark and Lindquist (2006) demonstrate that the association between current and lifetime income varies strongly over the life-cycle. When this is true, the use of current income as a proxy for lifetime income leads to inconsistent parameter estimates, also known as life-cycle bias, even when the proxy is used as the dependent variable.

Although this possibility has not been discussed in the previous literature, sibling correlations that use a single- or even a multiple-year measure of current income as a proxy for permanent income status will most likely suffer from this life-cycle bias. The following, rather simple income generating process can be used to illustrate the basic idea underlying life-cycle bias in the context of sibling correlations.

Imagine that parents in family $i$ invest an equal amount in each of their $j$ children and that this investment allows their children to earn at least $\alpha_{i}$ upon entering the labor market. This initial human capital endowment may vary across families by $\sigma_{\alpha}{ }^{2}$. Upon entering the labor market, each sibling actively manages his or her endowment by making decisions about hours worked, careers, further investments in human capital, etc. These choices allow their income to grow at a rate of $\gamma_{\mathrm{ij}}$ that may vary across choices made and individuals by $\sigma_{\gamma}{ }^{2}$. This income generating process can be written as

$y_{i j t}=\alpha_{i}+\gamma_{i j} t$. 
In a two-period model, the income of child $j$ in family $i$ in period 1 is

$y_{i j 1}=\alpha_{i}+\gamma_{i j}$,

with variance

$\operatorname{Var}\left(y_{i j 1}\right)=\sigma_{\alpha}^{2}+\sigma_{\gamma}^{2}$

assuming that $\alpha$ and $\gamma$ have a zero covariance.

The sibling correlation calculated using current, period-1 income is

$\rho_{1}=\frac{\sigma_{\alpha}^{2}}{\sigma_{\alpha}^{2}+\sigma_{\gamma}^{2}}$

Income of child $j$ in family $i$ in period 2 is

$y_{i j 2}=\alpha_{i}+\gamma_{i j} 2$,

with variance

$\operatorname{Var}\left(y_{i j 2}\right)=\sigma_{\alpha}^{2}+4 \sigma_{\gamma}^{2}$

The sibling correlation calculated using current, period-2 income is

$\rho_{2}=\frac{\sigma_{\alpha}^{2}}{\sigma_{\alpha}^{2}+4 \sigma_{\gamma}^{2}}$

The average, long-run income of sibling $j$ in family $i$ is given by ${ }^{16}$

$y_{i j}=1 / 2\left(\alpha_{i}+\gamma_{i j}+\alpha_{i}+\gamma_{i j} 2\right)=\alpha_{i}+3 / 2 \gamma_{i j}$,

with variance:

$\operatorname{Var}\left(y_{i j}\right)=\sigma_{\alpha}^{2}+9 / 4 \sigma_{\gamma}^{2}$.

The sibling correlation calculated using permanent income is

$$
\rho=\frac{\sigma_{\alpha}^{2}}{\sigma_{\alpha}^{2}+\frac{9}{4} \sigma_{\gamma}^{2}} .
$$

In this simple two-period model, the true sibling correlation is under estimated using early observations and over estimated using late one, i.e., $\rho_{1}>\rho>\rho_{2}$.

Using current income as a proxy for long-run income produces a biased estimate of the sibling correlation, if what we are interested in is the effect of family background

\footnotetext{
${ }^{16}$ Without loss of generality we can assume that agents do not discount period-2 income.
} 
effects on permanent income status. In this particular example, we overestimate the similarity between siblings when they are young and underestimate it when they are old. This bias is due to the existence of heterogeneous income paths over the life cycle, i.e. to the fact that returns to human capital investments, $\gamma_{i j}$, are allowed to vary across siblings and over time. This bias differs from the deterministic age and cohort effects discussed in Solon et al. (1991) and Mazumder (2007) in so much that it cannot be eliminated by adding fixed effects in age or years, since it is due to variations around the central tendency.

It is important to keep in mind, however, that this simple example is only one of many possible income generating processes. The model above assumes that all siblings start off identical and become more different over time, as assumption embodied in a zero covariance between the intercept and the growth rate. But it could be the case that siblings start off different and become more similar over time, or that between family differences rise or fall over time, which would affect our estimates of the sibling correlation through changes in $\sigma_{\alpha}{ }^{2}$. Each of these possible scenarios would affect our estimate of the sibling correlation in long-run income differently.

Our solution to this problem in this study is to stick to measuring income at the same ages for all cohort groups. If lifecycle bias is present but reasonably constant over time, our conclusions about trends will not be affected. Our choice has been to have income centered around age 34, an appropriate choice in Sweden, based on Böhlmark and Lindquist's (2006) examination of the association between annual and lifetime income. 
Table 1. Sample Descriptives by Cohort.

\begin{tabular}{|c|c|c|c|c|c|c|}
\hline $\begin{array}{l}\text { (Cohort) } \\
\text { Born }\end{array}$ & $\begin{array}{l}\text { Years when } \\
\text { income is } \\
\text { observed }\end{array}$ & $\begin{array}{l}\text { Mean age at } \\
\text { which } \\
\text { income is } \\
\text { observed }\end{array}$ & $\begin{array}{l}\text { Number } \\
\text { of } \\
\text { families }\end{array}$ & $\begin{array}{l}\text { Number of } \\
\text { individuals }\end{array}$ & $\begin{array}{c}\text { Log } \\
\text { annual } \\
\text { income }^{\mathrm{a}}\end{array}$ & $\begin{array}{l}\text { Average number } \\
\text { of income } \\
\text { observations per } \\
\text { individual; } \\
\text { fraction of zero } \\
\text { income } \\
\text { observations. }\end{array}$ \\
\hline $\begin{array}{l}(1) \\
1932- \\
1938\end{array}$ & 1968-1976 & $\begin{array}{c}34.9 \\
(2.4)^{b}\end{array}$ & 67555 & 81793 & $\begin{array}{l}9.65 \\
(.47)\end{array}$ & 5.5;.031 \\
\hline $\begin{array}{l}(2) \\
1935- \\
1941\end{array}$ & 1968-1979 & $\begin{array}{l}34.5 \\
(2.5)\end{array}$ & 98476 & 120498 & $\begin{array}{l}9.66 \\
(.47)\end{array}$ & 7.1; .027 \\
\hline $\begin{array}{l}(3) \\
1938- \\
1944\end{array}$ & 1968-1982 & $\begin{array}{l}34.1 \\
(2.6)\end{array}$ & 133597 & 164425 & $\begin{array}{l}9.66 \\
(.49)\end{array}$ & 8.3; .021 \\
\hline $\begin{array}{l}(4) \\
1941- \\
1947\end{array}$ & 1971-1985 & $\begin{array}{l}34.0 \\
(2.6)\end{array}$ & 165464 & 204111 & $\begin{array}{l}9.63 \\
(.51)\end{array}$ & $8.7 ; .014$ \\
\hline $\begin{array}{l}(5) \\
1944- \\
1950\end{array}$ & 1974-1988 & $\begin{array}{l}34.0 \\
(2.6)\end{array}$ & 181053 & 221773 & $\begin{array}{l}9.58 \\
(.53)\end{array}$ & $8.9 ; .009$ \\
\hline $\begin{array}{l}(6) \\
1947- \\
1953\end{array}$ & 1977-1991 & $\begin{array}{l}34.0 \\
(3.7)\end{array}$ & 177489 & 214537 & $\begin{array}{l}9.55 \\
(.56)\end{array}$ & $8.9 ; .007$ \\
\hline $\begin{array}{l}(7) \\
1950- \\
1956\end{array}$ & $1980-1994$ & $\begin{array}{l}34.0 \\
(3.7)\end{array}$ & 171608 & 206637 & $\begin{array}{l}9.56 \\
(.59)\end{array}$ & $8.9 ; .008$ \\
\hline $\begin{array}{l}(8) \\
1953- \\
1959\end{array}$ & 1983-1997 & $\begin{array}{l}34.0 \\
(2.6)\end{array}$ & 170336 & 205349 & $\begin{array}{l}9.59 \\
(.62)\end{array}$ & $8.9 ; .010$ \\
\hline $\begin{array}{l}(9) \\
1956- \\
1962\end{array}$ & $1986-2000$ & $\begin{array}{l}34.0 \\
(2.6)\end{array}$ & 168320 & 202565 & $\begin{array}{l}9.61 \\
(.66)\end{array}$ & 8.8;.014 \\
\hline $\begin{array}{l}(10) \\
1959- \\
1965\end{array}$ & 1989-2002 & $\begin{array}{l}33.9 \\
(2.6)\end{array}$ & 167132 & 202933 & $\begin{array}{l}9.66 \\
(.69)\end{array}$ & $8.7 ; .017$ \\
\hline $\begin{array}{l}(11) \\
1962- \\
1968\end{array}$ & $1992-2002$ & $\begin{array}{l}33.5 \\
(2.4)\end{array}$ & 150030 & 182696 & $\begin{array}{l}9.70 \\
(.69)\end{array}$ & 8.7; .018 \\
\hline
\end{tabular}
(a) The mean and standard deviation of annual income is measured for all observations used in the estimations.
(b) Numbers in parentheses are standard deviations. 
Table 2. Schooling and Returns to Schooling by Cohort.

\begin{tabular}{|c|c|c|c|c|c|c|c|c|c|}
\hline \multirow{2}{*}{$\begin{array}{l}\text { (Cohort) } \\
\text { Born }\end{array}$} & \multirow{2}{*}{$\begin{array}{c}\text { Mean years } \\
\text { of } \\
\text { schooling }\end{array}$} & \multicolumn{7}{|c|}{$\begin{array}{l}\text { Number of individuals in sample with } n \text { years of } \\
\text { schooling. \% of sample cohort. }\end{array}$} & \multirow{2}{*}{$\begin{array}{l}\text { Income } \\
\text { Returns }\end{array}$} \\
\hline & & 7 & 9 & 11 & 12 & 14 & 15.5 & 19 & \\
\hline $\begin{array}{l}(1) \\
1932- \\
1938\end{array}$ & $\begin{array}{l}9.45 \\
(2.91)^{\mathrm{a}}\end{array}$ & $\begin{array}{c}47675 \\
52 \%\end{array}$ & $\begin{array}{l}4400 \\
5 \%\end{array}$ & $\begin{array}{c}17755 \\
19 \%\end{array}$ & $\begin{array}{c}11538 \\
13 \%\end{array}$ & $\begin{array}{c}3308 \\
4 \%\end{array}$ & $\begin{array}{l}6656 \\
7 \%\end{array}$ & $\begin{array}{l}671 \\
1 \%\end{array}$ & $\begin{array}{l}.069 \\
(.001)\end{array}$ \\
\hline $\begin{array}{l}(2) \\
1935- \\
1941\end{array}$ & $\begin{array}{c}9.84 \\
(3.02)\end{array}$ & $\begin{array}{c}59583 \\
45 \%\end{array}$ & $\begin{array}{c}6793 \\
5 \%\end{array}$ & $\begin{array}{c}27023 \\
21 \%\end{array}$ & $\begin{array}{c}18336 \\
14 \%\end{array}$ & $\begin{array}{c}6693 \\
5 \%\end{array}$ & $\begin{array}{c}11321 \\
9 \%\end{array}$ & $\begin{array}{c}1263 \\
1 \%\end{array}$ & $\begin{array}{l}.058 \\
(.000)\end{array}$ \\
\hline $\begin{array}{l}(3) \\
1938- \\
1944\end{array}$ & $\begin{array}{l}10.41 \\
(3.11)\end{array}$ & $\begin{array}{c}63645 \\
36 \%\end{array}$ & $\begin{array}{c}10243 \\
6 \%\end{array}$ & $\begin{array}{c}38838 \\
22 \%\end{array}$ & $\begin{array}{c}27006 \\
15 \%\end{array}$ & $\begin{array}{c}12635 \\
7 \%\end{array}$ & $\begin{array}{c}19832 \\
11 \%\end{array}$ & $\begin{array}{c}2213 \\
1 \%\end{array}$ & $\begin{array}{c}.046 \\
(.000)\end{array}$ \\
\hline $\begin{array}{l}(4) \\
1941- \\
1947\end{array}$ & $\begin{array}{l}10.82 \\
(3.06)\end{array}$ & $\begin{array}{c}61467 \\
29 \%\end{array}$ & $\begin{array}{c}16276 \\
8 \%\end{array}$ & $\begin{array}{c}51184 \\
24 \%\end{array}$ & $\begin{array}{c}34949 \\
16 \%\end{array}$ & $\begin{array}{c}18115 \\
8 \%\end{array}$ & $\begin{array}{c}28588 \\
13 \%\end{array}$ & $\begin{array}{c}2744 \\
1 \%\end{array}$ & $\begin{array}{c}.041 \\
(.000)\end{array}$ \\
\hline $\begin{array}{l}(5) \\
1944- \\
1950\end{array}$ & $\begin{array}{l}11.08 \\
(2.91)\end{array}$ & $\begin{array}{c}49925 \\
22 \%\end{array}$ & $\begin{array}{c}25423 \\
11 \%\end{array}$ & $\begin{array}{c}59375 \\
26 \%\end{array}$ & $\begin{array}{c}37896 \\
17 \%\end{array}$ & $\begin{array}{c}21726 \\
9 \%\end{array}$ & $\begin{array}{c}32200 \\
14 \%\end{array}$ & $\begin{array}{c}2497 \\
1 \%\end{array}$ & $\begin{array}{c}.039 \\
(.000)\end{array}$ \\
\hline $\begin{array}{l}(6) \\
1947- \\
1953\end{array}$ & $\begin{array}{c}11.32 \\
(2.71)\end{array}$ & $\begin{array}{c}30305 \\
14 \%\end{array}$ & $\begin{array}{c}35400 \\
16 \%\end{array}$ & $\begin{array}{c}63159 \\
29 \%\end{array}$ & $\begin{array}{c}33343 \\
15 \%\end{array}$ & $\begin{array}{c}24733 \\
11 \%\end{array}$ & $\begin{array}{c}30747 \\
14 \%\end{array}$ & $\begin{array}{c}2125 \\
1 \%\end{array}$ & $\begin{array}{c}.041 \\
(.000)\end{array}$ \\
\hline $\begin{array}{l}(7) \\
1950- \\
1956\end{array}$ & $\begin{array}{l}11.49 \\
(2.48)\end{array}$ & $\begin{array}{c}13885 \\
7 \%\end{array}$ & $\begin{array}{c}44112 \\
21 \%\end{array}$ & $\begin{array}{c}69345 \\
33 \%\end{array}$ & $\begin{array}{c}26537 \\
13 \%\end{array}$ & $\begin{array}{c}26520 \\
13 \%\end{array}$ & $\begin{array}{c}27890 \\
13 \%\end{array}$ & $\begin{array}{c}1755 \\
1 \%\end{array}$ & $\begin{array}{c}.047 \\
(.000)\end{array}$ \\
\hline $\begin{array}{l}(8) \\
1953- \\
1959\end{array}$ & $\begin{array}{l}11.57 \\
(2.29)\end{array}$ & $\begin{array}{c}4667 \\
2 \%\end{array}$ & $\begin{array}{c}47675 \\
23 \%\end{array}$ & $\begin{array}{c}78335 \\
38 \%\end{array}$ & $\begin{array}{c}22369 \\
11 \%\end{array}$ & $\begin{array}{c}26208 \\
13 \%\end{array}$ & $\begin{array}{c}26589 \\
13 \%\end{array}$ & $\begin{array}{c}1367 \\
1 \%\end{array}$ & $\begin{array}{c}.057 \\
(.001)\end{array}$ \\
\hline $\begin{array}{l}(9) \\
1956- \\
1962\end{array}$ & $\begin{array}{l}11.68 \\
(2.19)\end{array}$ & $\begin{array}{c}1654 \\
1 \%\end{array}$ & $\begin{array}{c}41473 \\
21 \%\end{array}$ & $\begin{array}{c}84541 \\
42 \%\end{array}$ & $\begin{array}{c}20571 \\
10 \%\end{array}$ & $\begin{array}{c}27142 \\
13 \%\end{array}$ & $\begin{array}{c}25168 \\
12 \%\end{array}$ & $\begin{array}{c}1521 \\
1 \%\end{array}$ & $\begin{array}{c}.065 \\
(.001)\end{array}$ \\
\hline $\begin{array}{l}(10) \\
1959- \\
1965\end{array}$ & $\begin{array}{l}11.79 \\
(2.15)\end{array}$ & $\begin{array}{c}1194 \\
1 \%\end{array}$ & $\begin{array}{c}35114 \\
17 \%\end{array}$ & $\begin{array}{c}88384 \\
44 \%\end{array}$ & $\begin{array}{c}20036 \\
10 \%\end{array}$ & $\begin{array}{c}30303 \\
15 \%\end{array}$ & $\begin{array}{c}23999 \\
12 \%\end{array}$ & $\begin{array}{c}1813 \\
1 \%\end{array}$ & $\begin{array}{c}.068 \\
(.001)\end{array}$ \\
\hline $\begin{array}{l}(11) \\
1962- \\
1968 \\
\end{array}$ & $\begin{array}{l}11.85 \\
(2.10)\end{array}$ & $\begin{array}{l}765 \\
0 \%\end{array}$ & $\begin{array}{c}27881 \\
15 \%\end{array}$ & $\begin{array}{c}82363 \\
46 \%\end{array}$ & $\begin{array}{c}17866 \\
10 \%\end{array}$ & $\begin{array}{c}29913 \\
17 \%\end{array}$ & $\begin{array}{c}20373 \\
11 \%\end{array}$ & $\begin{array}{c}1551 \\
1 \%\end{array}$ & $\begin{array}{c}.068 \\
(.001)\end{array}$ \\
\hline
\end{tabular}

(a) Numbers in parentheses are standard deviations. 
Table 3. Number of Brothers per Family and Age Difference between Brothers by Cohort.

\begin{tabular}{|c|c|c|c|c|c|}
\hline $\begin{array}{l}\text { (Cohort) } \\
\text { Born }\end{array}$ & $\begin{array}{c}\text { Average number } \\
\text { of brothers per } \\
\text { family }\end{array}$ & $\begin{array}{l}\text { Average age } \\
\text { difference }\end{array}$ & $\begin{array}{l}\text { (Cohort) } \\
\text { Born }\end{array}$ & $\begin{array}{c}\text { Average number } \\
\text { of brothers per } \\
\text { family } \\
\end{array}$ & $\begin{array}{c}\text { Average age } \\
\text { difference }\end{array}$ \\
\hline (1) & & & (7) & & \\
\hline $\begin{array}{l}1932- \\
1938\end{array}$ & 1.21 & 2.52 & $\begin{array}{l}1950- \\
1956\end{array}$ & 1.20 & 2.71 \\
\hline$(2)$ & & & $(8)$ & & \\
\hline $\begin{array}{l}1935- \\
1941\end{array}$ & 1.22 & 2.67 & $\begin{array}{l}1953- \\
1959\end{array}$ & 1.21 & 2.70 \\
\hline (3) & & & (9) & & \\
\hline $\begin{array}{l}1938- \\
1944 \\
(4)\end{array}$ & 1.23 & 2.74 & $\begin{array}{l}1956- \\
1962 \\
(10)\end{array}$ & 1.20 & 2.72 \\
\hline $\begin{array}{l}1941- \\
1947 \\
(5)\end{array}$ & 1.23 & 2.69 & $\begin{array}{l}1959- \\
1965 \\
(11)\end{array}$ & 1.21 & 2.74 \\
\hline $\begin{array}{l}1944- \\
1950\end{array}$ & 1.22 & 2.71 & $\begin{array}{l}1962- \\
1965\end{array}$ & 1.22 & 2.64 \\
\hline $\begin{array}{l}(6) \\
1947- \\
1953\end{array}$ & 1.21 & 2.71 & & & \\
\hline
\end{tabular}


Table A1. Baseline Estimations.

\begin{tabular}{|c|c|c|c|c|c|}
\hline $\begin{array}{c}\text { (Cohort) } \\
\text { Born }\end{array}$ & $\begin{array}{c}\text { Sibling } \\
\text { Correlation }\end{array}$ & $\begin{array}{c}\text { Family } \\
\text { Variation }\end{array}$ & $\begin{array}{c}\text { Individual } \\
\text { Variation }\end{array}$ & $\begin{array}{l}\text { Transitory } \\
\text { Variation }\end{array}$ & $\begin{array}{c}\text { Family Share } \\
\text { of Total } \\
\text { Variation } \\
\end{array}$ \\
\hline \multirow{2}{*}{$\begin{array}{c}(1) \\
1932-1938\end{array}$} & 0.344 & 0.063 & 0.012 & 0.061 & 0.258 \\
\hline & $(0.0082)^{\mathrm{a}}$ & $(0.0016)$ & $(0.0015)$ & $(0.0001)$ & $(0.0062)$ \\
\hline \multirow{2}{*}{$\begin{array}{c}(2) \\
1935-1941\end{array}$} & 0.314 & 0.054 & 0.119 & 0.071 & 0.223 \\
\hline & $(0.0065)$ & $(0.0012)$ & $(0.0012)$ & $(0.0001)$ & $(0.0047)$ \\
\hline \multirow{2}{*}{$\begin{array}{c}(3) \\
1938-1944\end{array}$} & 0.272 & 0.045 & 0.120 & 0.087 & 0.178 \\
\hline & $(0.0056)$ & $(0.0010)$ & $(0.0010)$ & $(0.0001)$ & $(0.0037)$ \\
\hline \multirow[t]{2}{*}{$\begin{array}{c}(4) \\
1941-1947\end{array}$} & 0.261 & 0.044 & 0.125 & 0.101 & 0.163 \\
\hline & $(0.0051)$ & $(0.0009)$ & $(0.0009)$ & $(0.0001)$ & $(0.0032)$ \\
\hline \multirow[t]{2}{*}{$\begin{array}{c}(5) \\
1944-1950\end{array}$} & 0.232 & 0.042 & 0.137 & 0.113 & 0.142 \\
\hline & $(0.0050)$ & $(0.0009)$ & $(0.0010)$ & $(0.0001)$ & $(0.0031)$ \\
\hline \multirow{2}{*}{$\begin{array}{c}(6) \\
1947-1953\end{array}$} & 0.233 & 0.045 & 0.150 & 0.130 & 0.140 \\
\hline & $(0.0053)$ & $(0.0011)$ & $(0.0011)$ & $(0.0001)$ & $(0.0032)$ \\
\hline \multirow{2}{*}{$\begin{array}{c}(7) \\
1950-1956\end{array}$} & 0.230 & 0.050 & 0.167 & 0.148 & 0.137 \\
\hline & $(0.0054)$ & $(0.0012)$ & $(0.0013)$ & $(0.0002)$ & $(0.0033)$ \\
\hline \multirow{2}{*}{$\begin{array}{c}(8) \\
1953-1959\end{array}$} & 0.255 & 0.064 & 0.186 & 0.167 & 0.153 \\
\hline & $(0.0053)$ & $(0.0014)$ & $(0.0014)$ & $(0.0002)$ & $(0.0032)$ \\
\hline \multirow[t]{2}{*}{$\begin{array}{c}(9) \\
1956-1962\end{array}$} & 0.236 & 0.069 & 0.225 & 0.181 & 0.146 \\
\hline & $(0.0053)$ & $(0.0016)$ & $(0.0017)$ & $(0.0002)$ & $(0.0033)$ \\
\hline \multirow{2}{*}{$\begin{array}{c}(10) \\
1959-1965\end{array}$} & 0.230 & 0.074 & 0.249 & 0.193 & 0.144 \\
\hline & $(0.0053)$ & $(0.0018)$ & $(0.0018)$ & $(0.0002)$ & $(0.0034)$ \\
\hline \multirow{2}{*}{$\begin{array}{c}(11) \\
1962-1968\end{array}$} & 0.220 & 0.072 & 0.256 & 0.193 & 0.138 \\
\hline & $(0.0056)$ & $(0.0019)$ & $(0.0020)$ & $(0.0002)$ & $(0.0036)$ \\
\hline
\end{tabular}

(a) Numbers in parentheses are standard errors. The standard errors of the sibling correlations and of the family share of total variation are calculated with the delta method using the nlcom command in STATA. 
Figure 1. Baseline estimates of brother correlations in income with $95 \%$ confidence intervals.

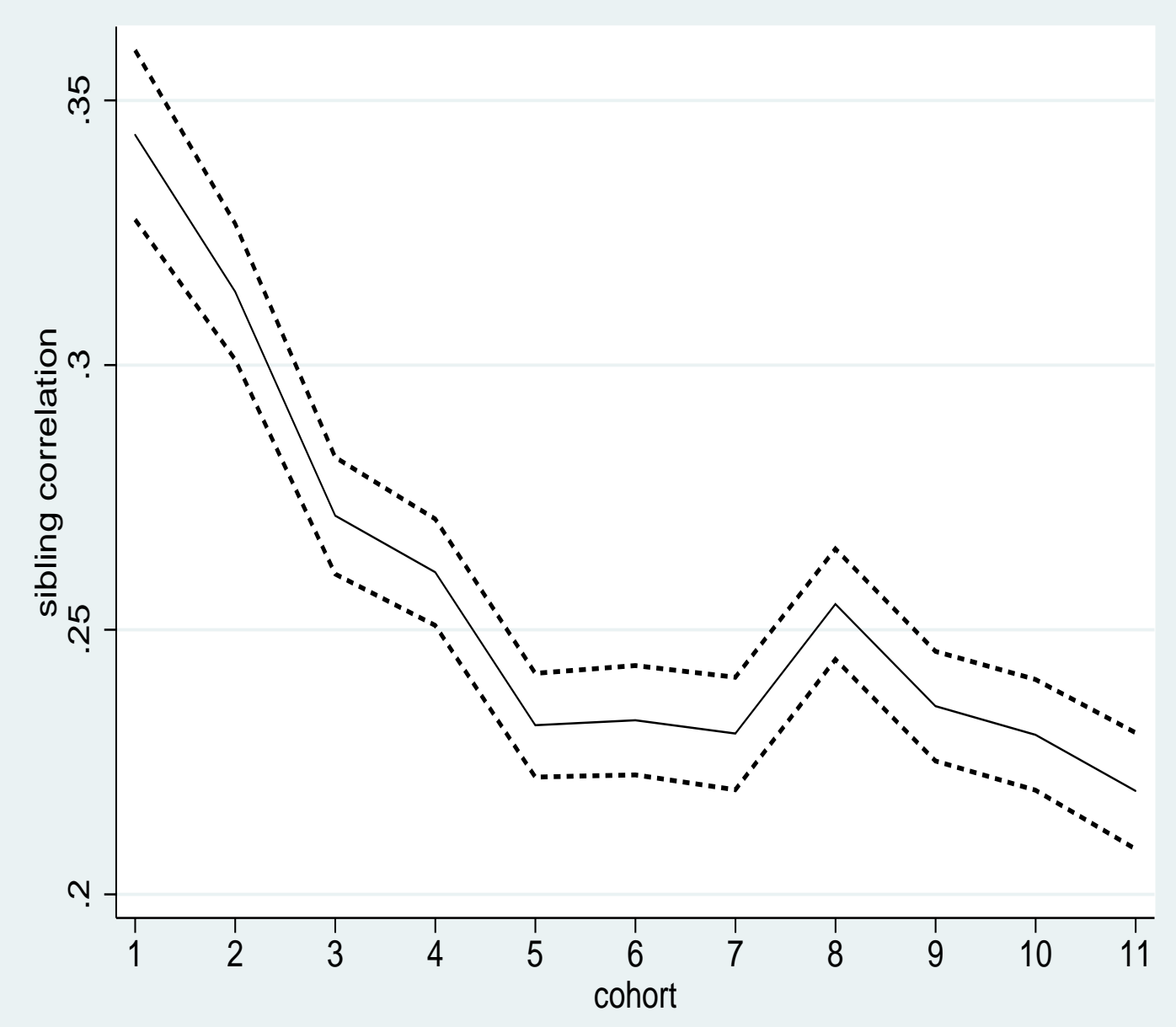

Note: The estimates of the sibling correlations as well as their corresponding standard errors are reported in Table A1. The standard errors of the sibling correlations are calculated with the delta method using the nlcom command in STATA. 
Figure 2. Estimated variance components for the baseline case.
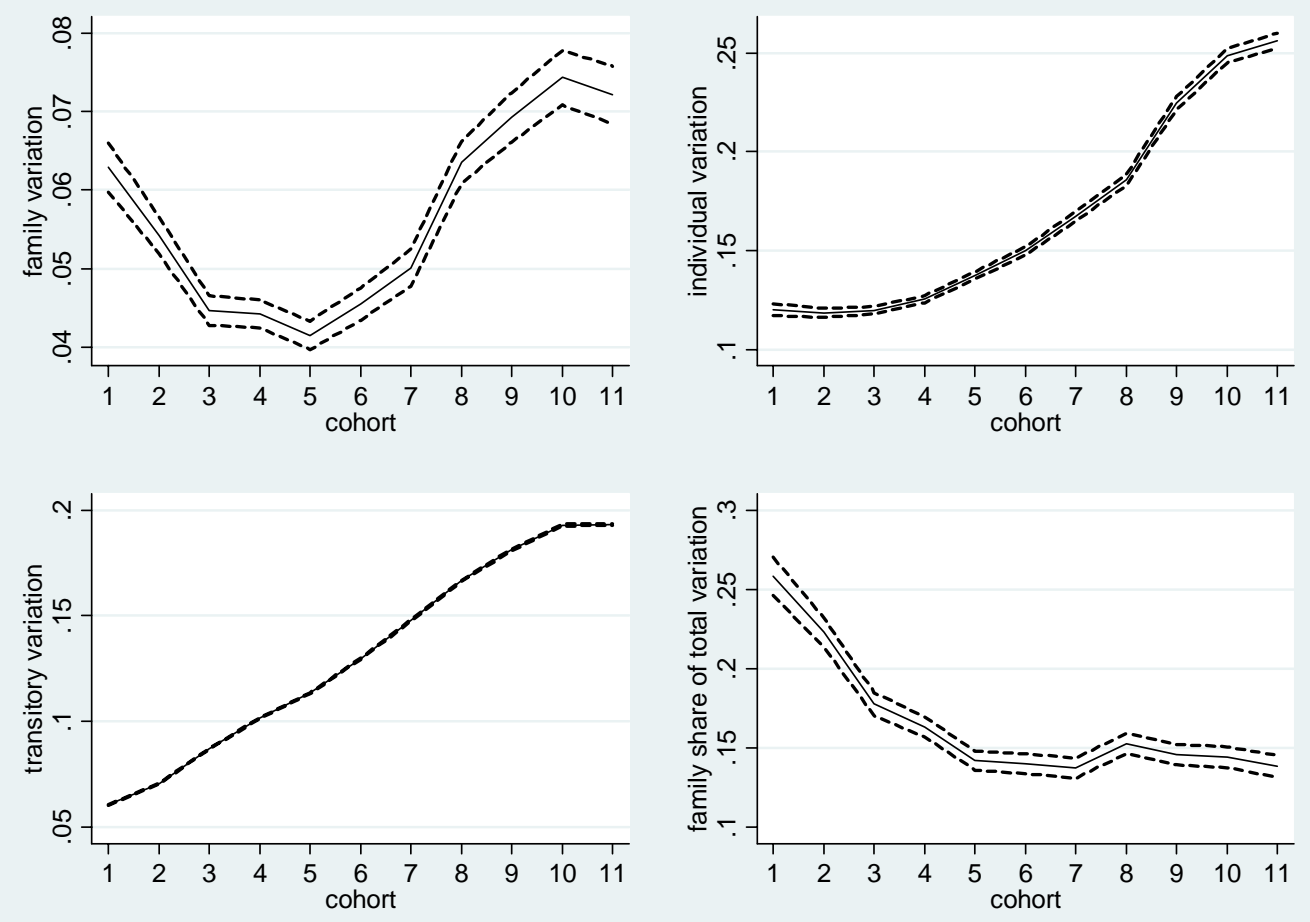

Note: The estimates of the variance components as well as their corresponding standard errors are reported in Table A1. The standard errors of the family share of total variance are calculated with the delta method using the nlcom command in STATA. 
Figure 3a. Sensitivity analysis of low income observations: setting missing values to SEK1.

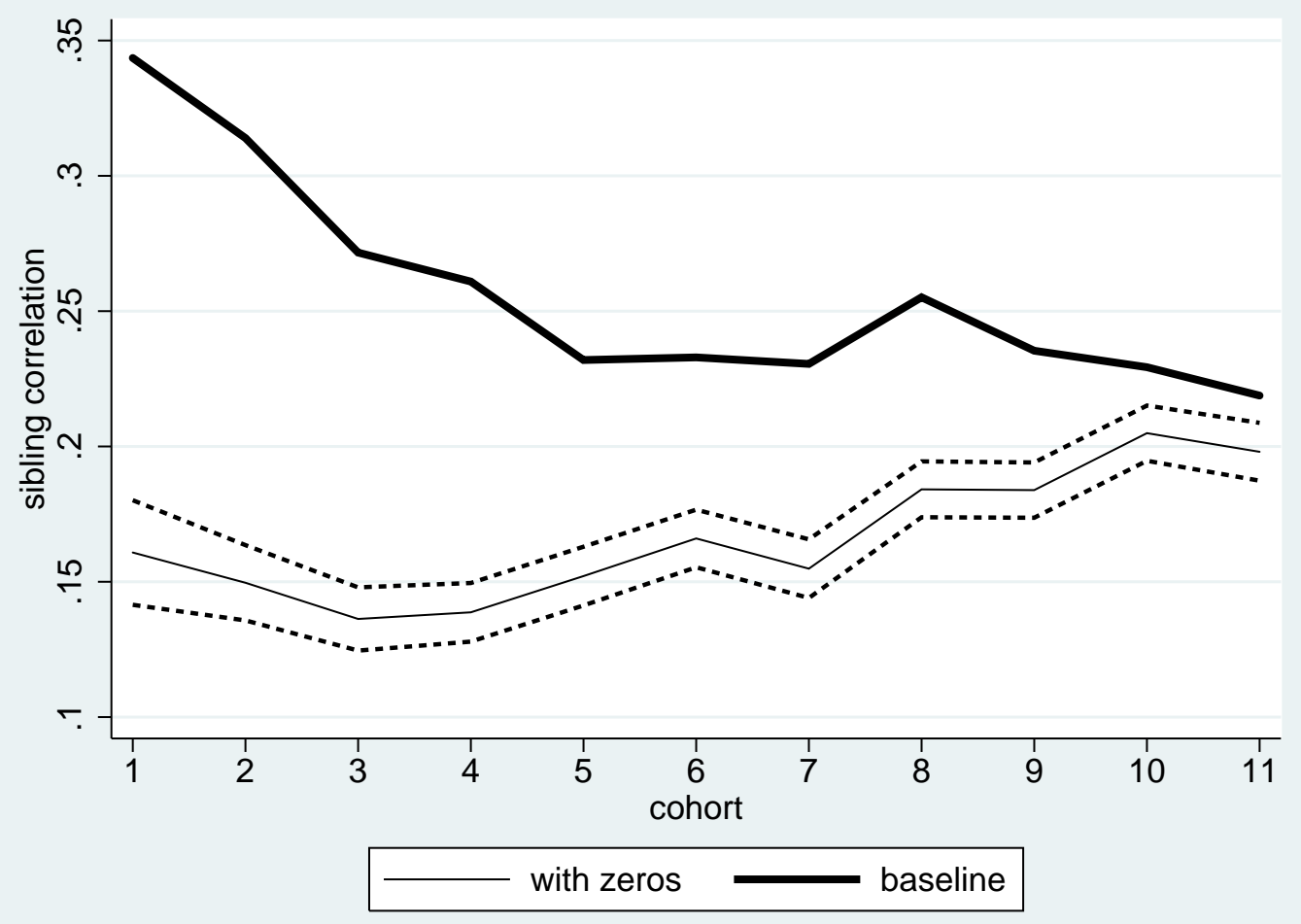

Figure 3b. Sensitivity analysis of low income observations: raising the lower income bound.

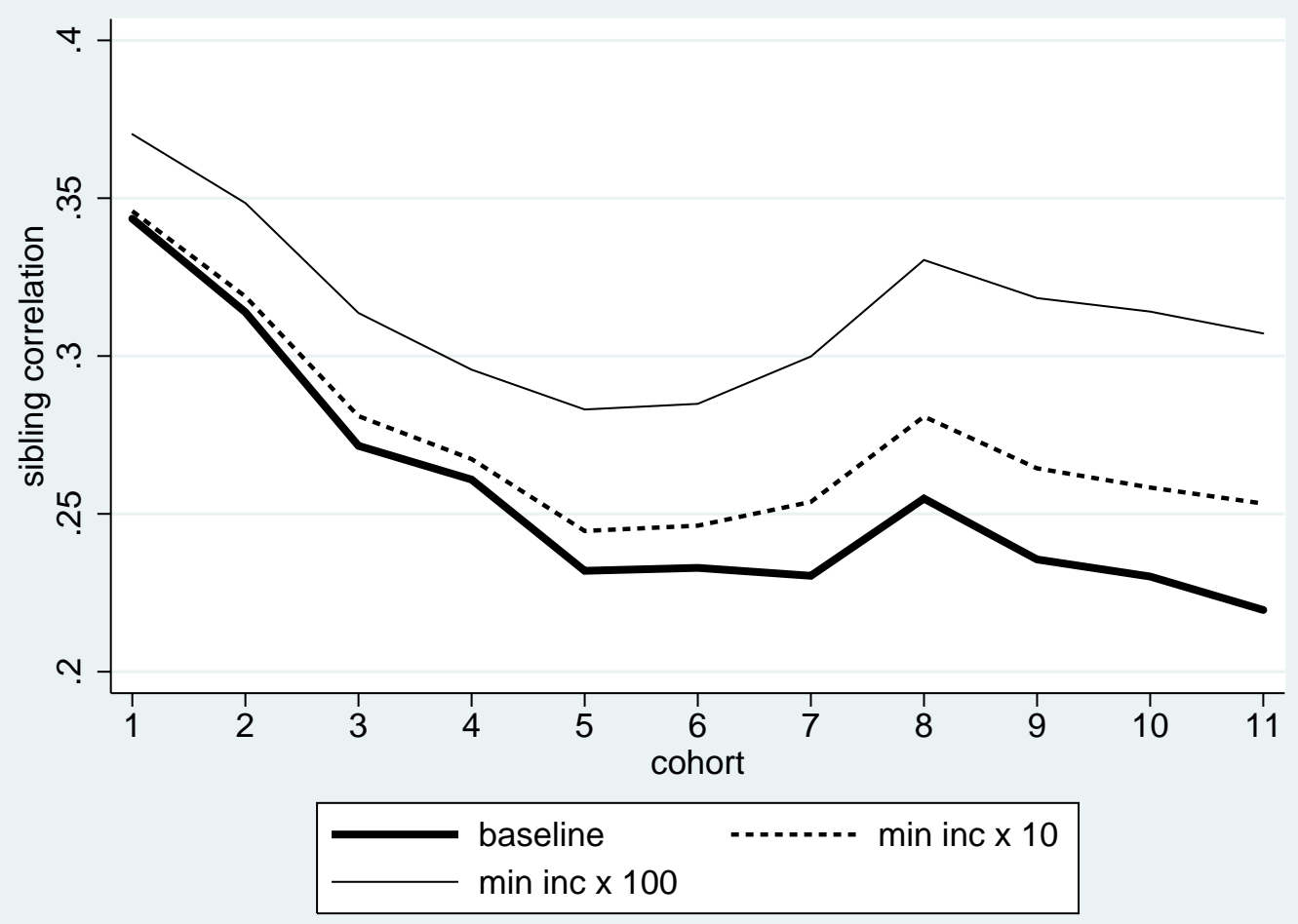


Figure 3c. Sensitivity analysis of low income observations: using the log of average income at ages $30-38$.

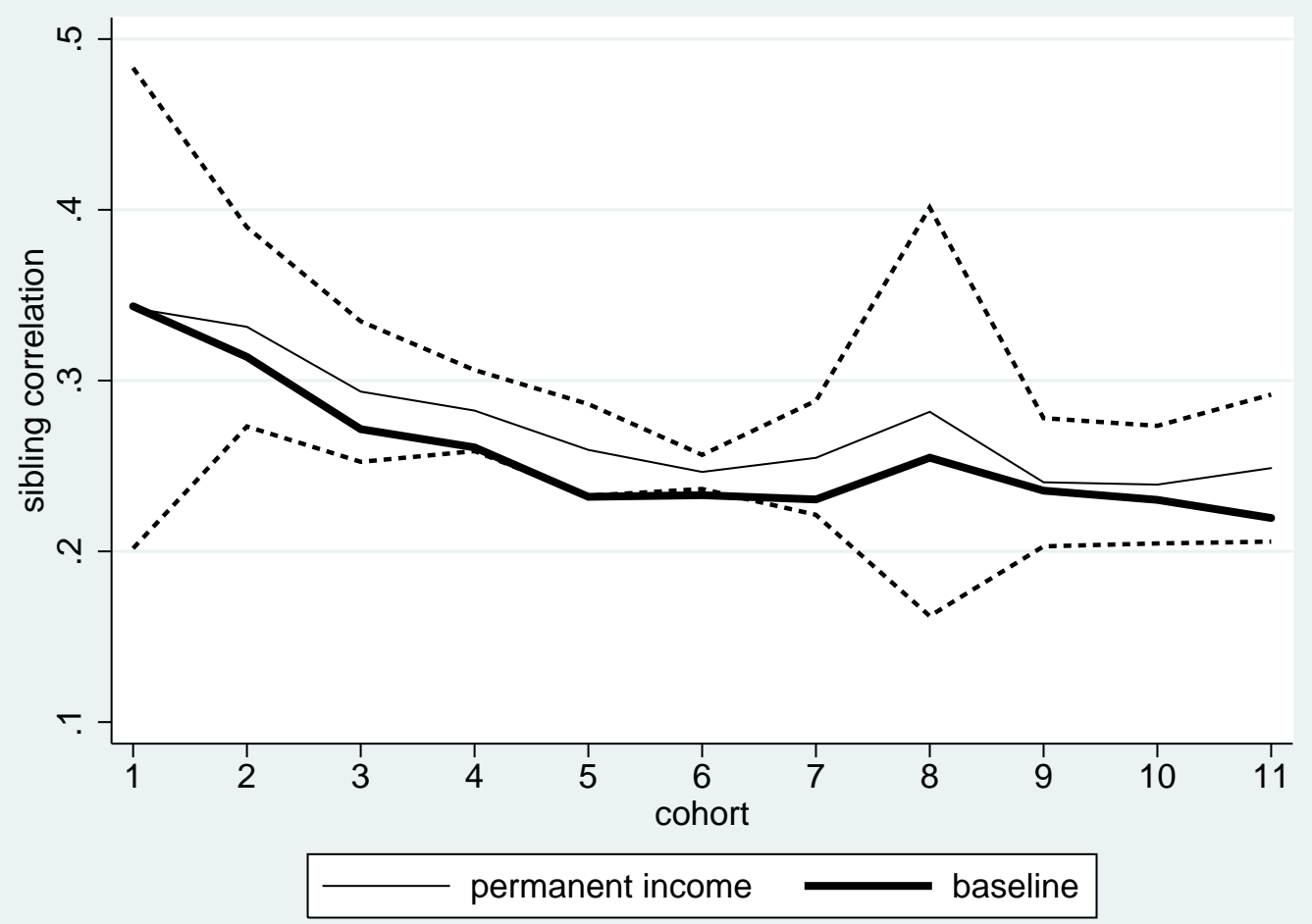


Figure 4. Sensitivity analysis of the impact of the age at income observations, 30-52 years instead of 30-38 in the baseline case.

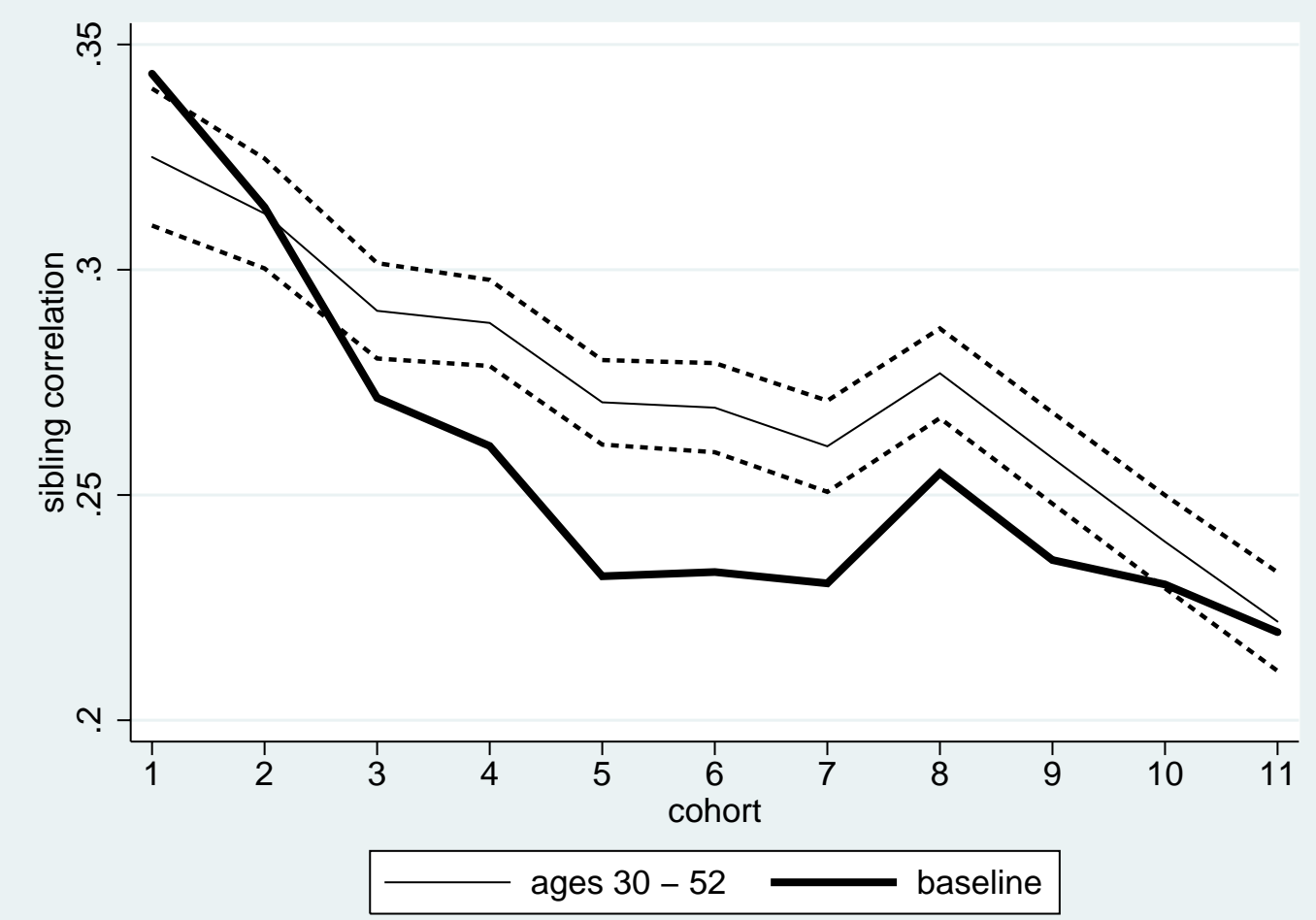


Figure 5. Sensitivity analysis of the impact of the change in the change in the income concept from 1973-74. Subtraction of UI and sickness benefits for the years 1974-1980.

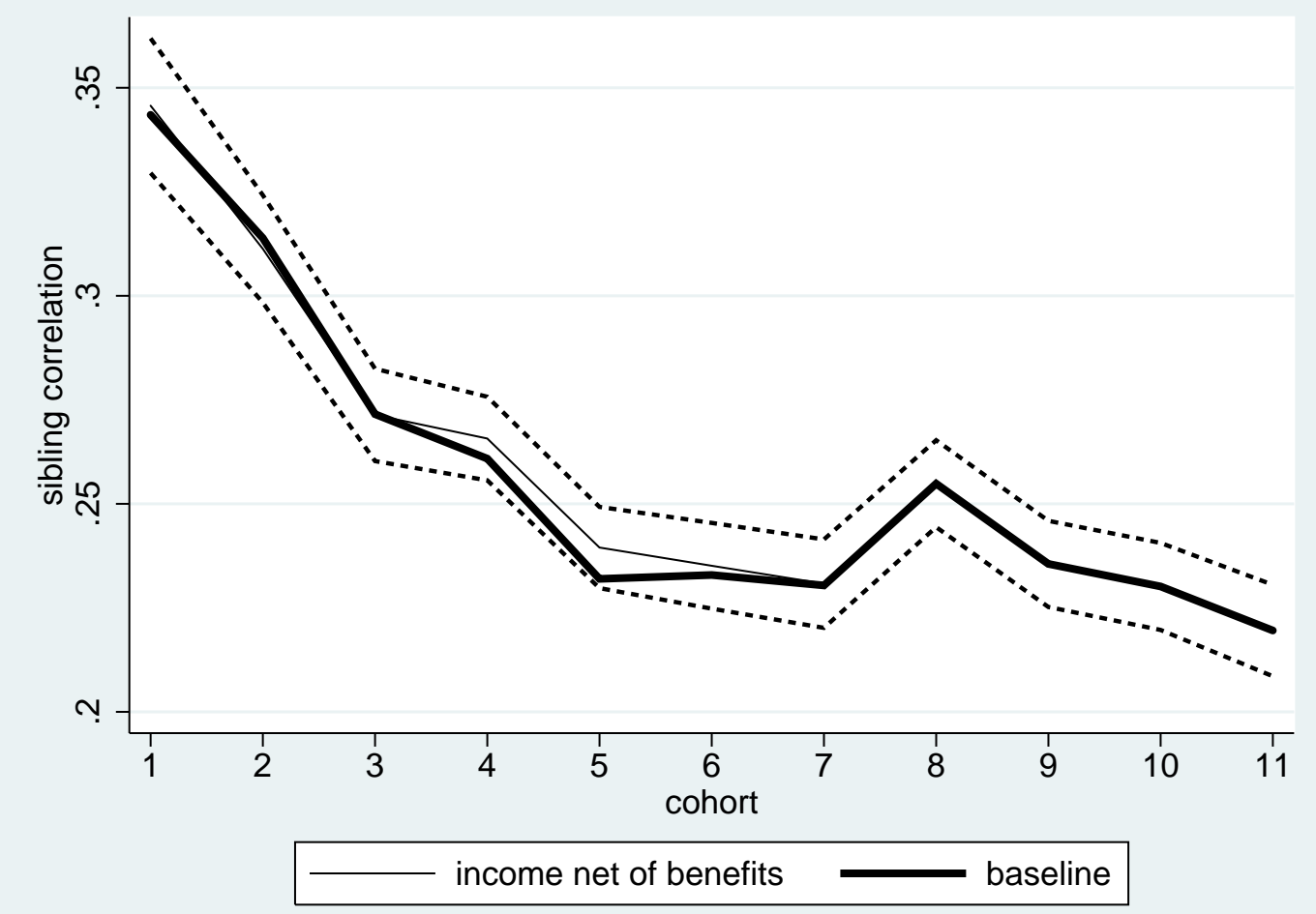


Figure 6. Sensitivity analysis allowing for an AR(1) process in the residuals.

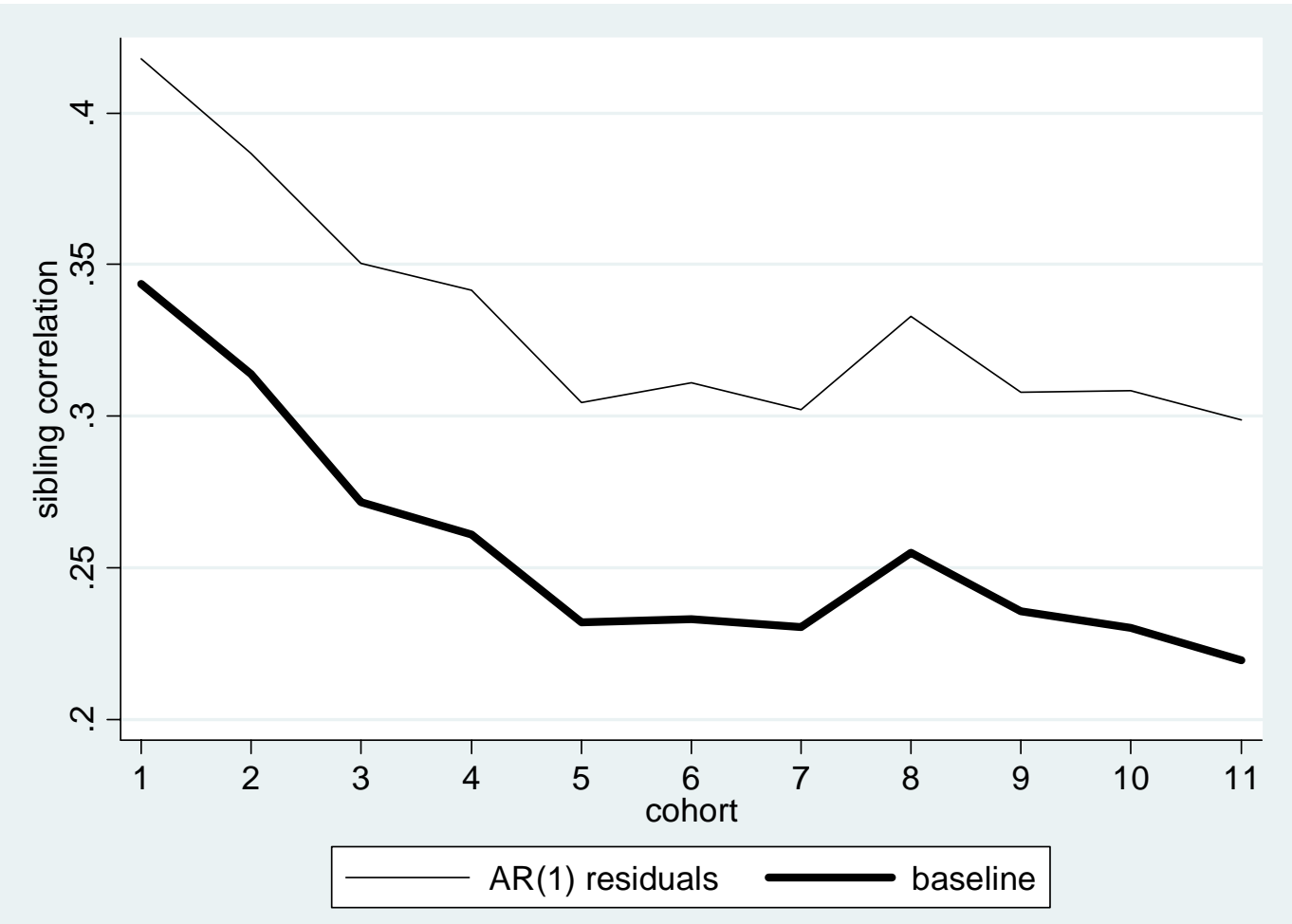


Figure 7. Income correlations controlling for the income impact of years of schooling.

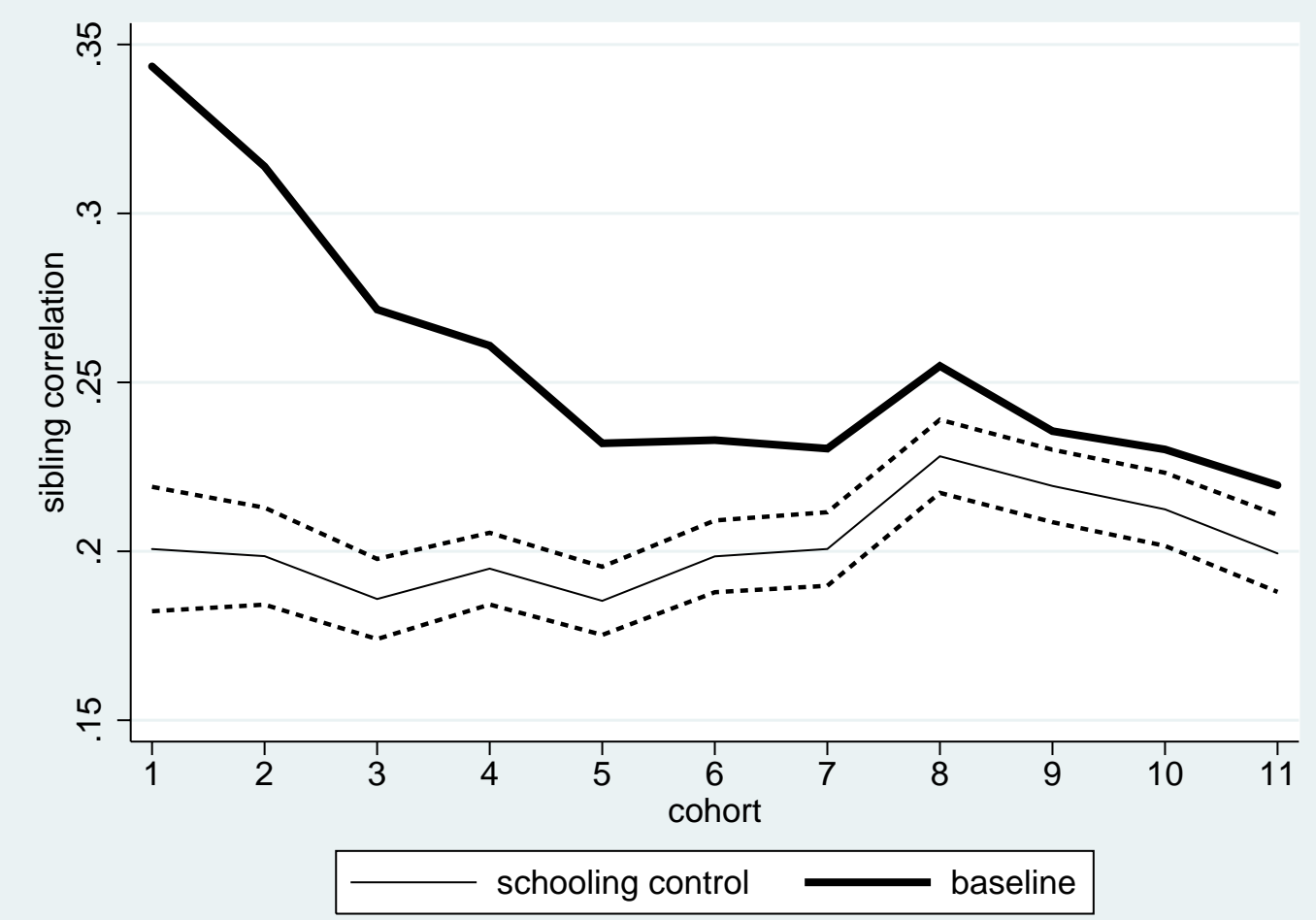


Figure 8. Brother correlations in years of schooling.

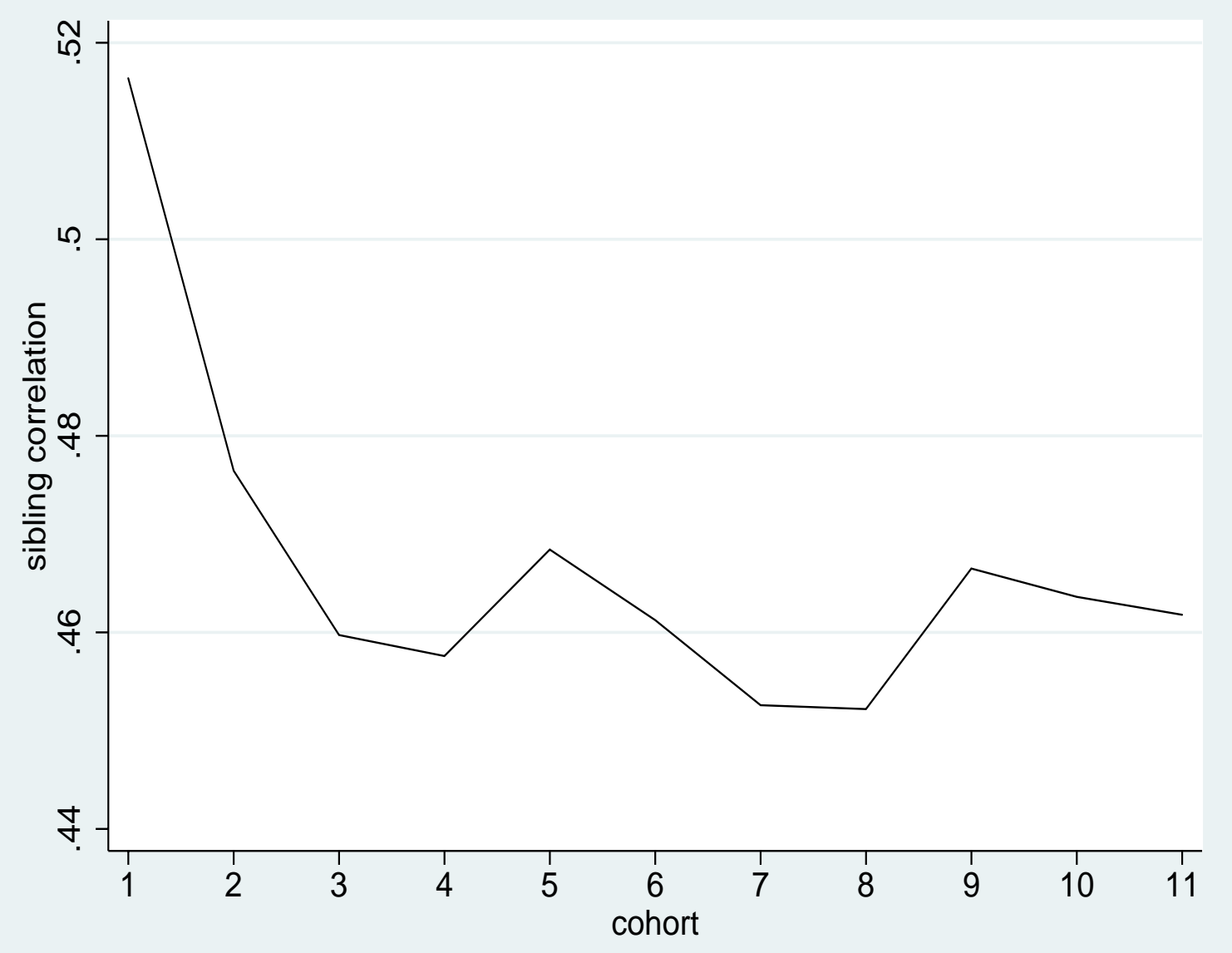


Figure 9. Brother correlation in income with constant returns to schooling.

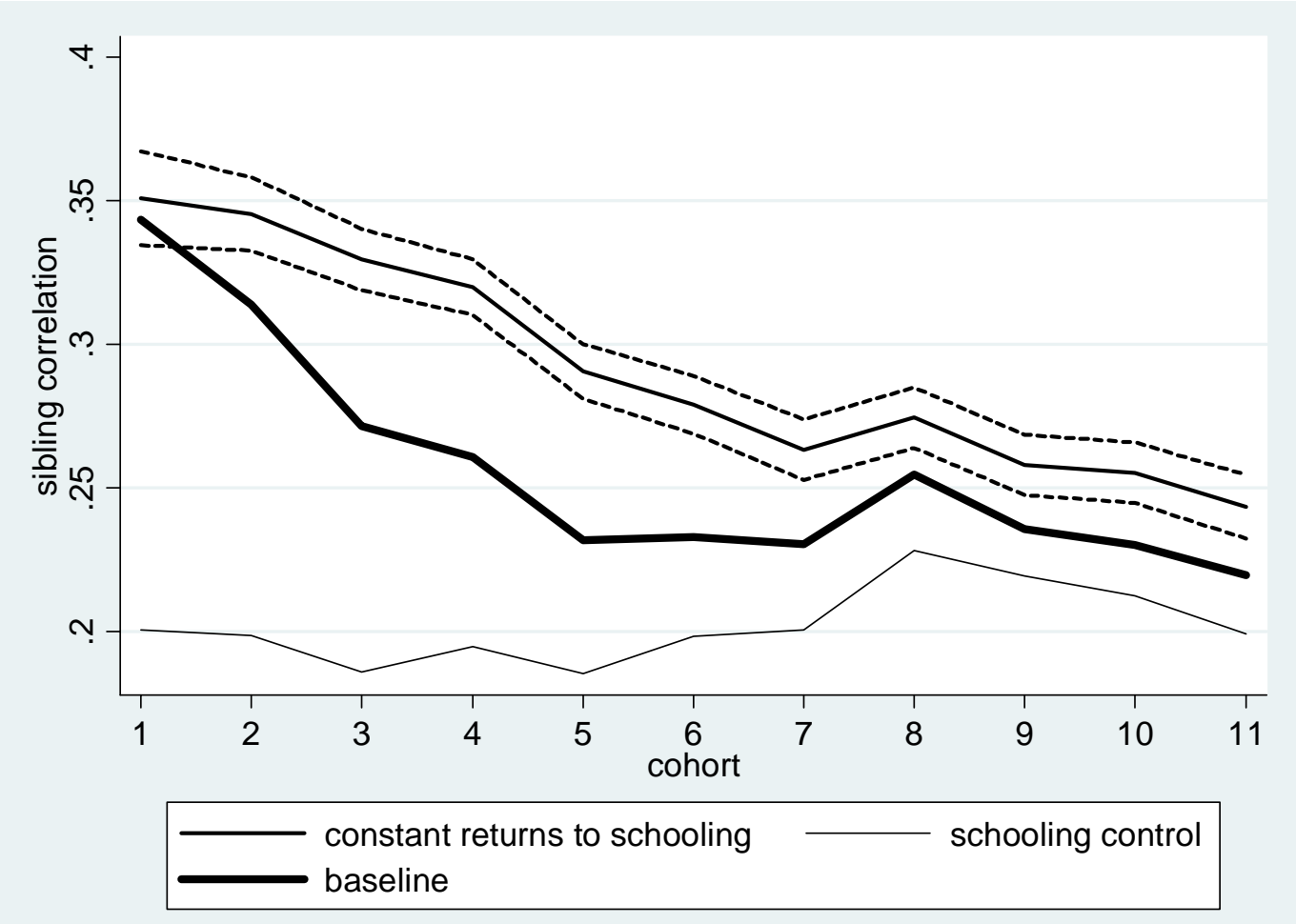

